\title{
Supplementing Art Therapy with Cognitive Behavioral Therapy (CBT) and Dialectical Behavior Therapy (DBT) during Treatment of Childhood Anxiety Disorders: A Pilot Study
}

Rachel Cecil

Follow this and additional works at: https://researchrepository.wvu.edu/etd

\section{Recommended Citation}

Cecil, Rachel, "Supplementing Art Therapy with Cognitive Behavioral Therapy (CBT) and Dialectical Behavior Therapy (DBT) during Treatment of Childhood Anxiety Disorders: A Pilot Study" (2016). Graduate Theses, Dissertations, and Problem Reports. 5328.

https://researchrepository.wvu.edu/etd/5328

This Thesis is protected by copyright and/or related rights. It has been brought to you by the The Research Repository @ WVU with permission from the rights-holder(s). You are free to use this Thesis in any way that is permitted by the copyright and related rights legislation that applies to your use. For other uses you must obtain permission from the rights-holder(s) directly, unless additional rights are indicated by a Creative Commons license in the record and/ or on the work itself. This Thesis has been accepted for inclusion in WVU Graduate Theses, Dissertations, and Problem Reports collection by an authorized administrator of The Research Repository @ WVU. For more information, please contact researchrepository@mail.wvu.edu. 
Supplementing Art Therapy with Cognitive Behavioral Therapy (CBT) and Dialectical Behavior Therapy (DBT) during Treatment of Childhood Anxiety Disorders: A Pilot Study

\section{Rachel Cecil}

Thesis Submitted to the College of Creative Arts at West Virginia University

in partial fulfillment of the requirements for the degree of

Masters of Arts in

Art Education

\section{Terese Giobbia, Ph.D., chair \\ Matthew Campbell, Ph.D. \\ Joseph Lupo, MFA}

\section{Morgantown, WV}

2016

Keywords: art therapy, cognitive behavioral therapy, dialectical behavior therapy, childhood anxiety disorders

Copyright, 2016 Rachel Cecil 


\section{ABSTRACT \\ Supplementing Art Therapy with Cognitive Behavioral Therapy (CBT) and Dialectical Behavior Therapy (DBT) during Treatment of Childhood Anxiety Disorders: A Pilot Study}

\section{Rachel Cecil}

A qualitative research study presents a thorough examination of one therapist's methods of supplementing art therapy with cognitive behavioral therapy (CBT) and dialectical behavior therapy (DBT) during the treatment of children impaired by a variety of anxiety disorders - i.e. generalized anxiety disorder (GAD), obsessive-compulsive disorder (OCD), and posttraumatic stress disorder (PSTD). A review of the existing literature was used to inform the current study. The researcher created an exploratory case study, through the utilization of a pilot study, to gain a better understanding of the topic from an expert in these therapeutic fields. Through the gathering of data and analysis, the findings suggest that supplementing art therapy with CBT and DBT during the treatment of children impaired by GAD, OCD, and PTSD has intrinsic value in reducing the symptoms exhibited in these anxiety disorders and can create an overall improvement in their quality of life. The pilot study provided a means to analyze these three therapeutic methods within the collaborative therapeutic model in a critical manner, allowing it to be researched further and implemented in the future. Drawing on her expertise in working with children impaired by these anxiety disorders, the therapist provided valuable feedback in supplementing art therapy with CBT and DBT during the treatment of these anxiety disorders. Combining these three therapeutic methods into a collaborative model has the potential to provide adequate treatment for childhood anxiety disorders amidst the negative impacts that a cognitive and/or behavioral disorder might evoke. 
Table of Contents

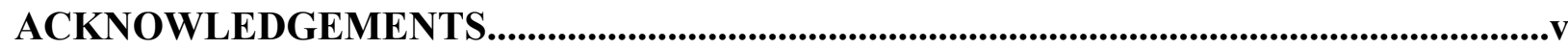

\section{CHAPTER 1- Introduction}

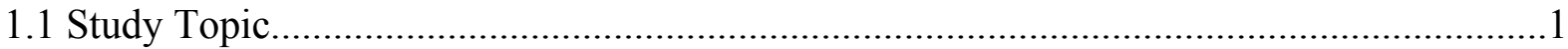

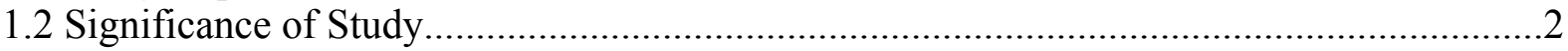

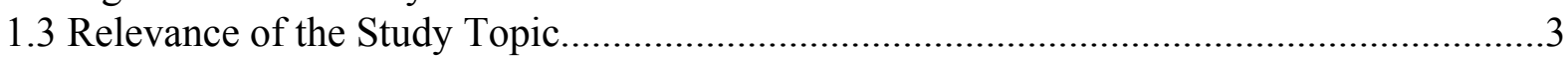

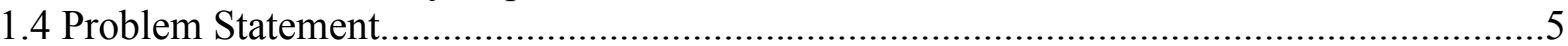

\section{CHAPTER 2- Literature Review}

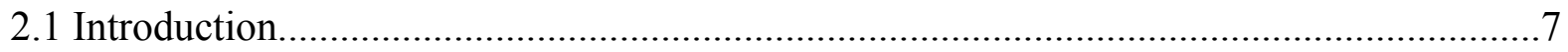

2.2 A Brief Overview of Childhood Anxiety Disorders............................................... 7

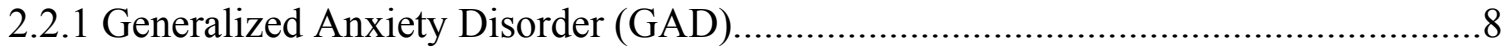

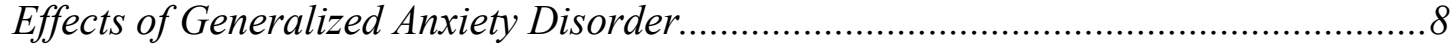

Causes of Generalized Anxiety Disorder.................................................................9

Symptoms of Generalized Anxiety Disorder............................................................ 9

Failure to Treat Generalized Anxiety Disorder........................................................ 10

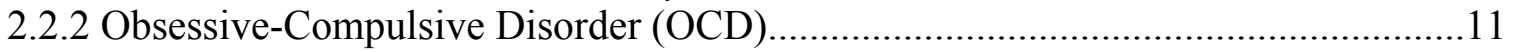

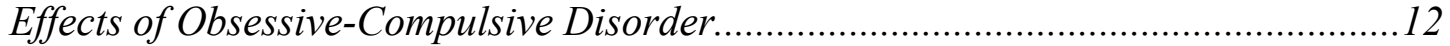

Causes of Obsessive-Compulsive Disorder.......................................................... 12

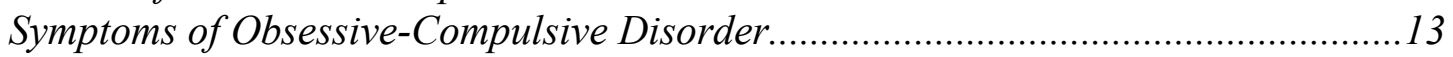

Failure to Treat Obsessive-Compulsive Disorder.................................................... 14

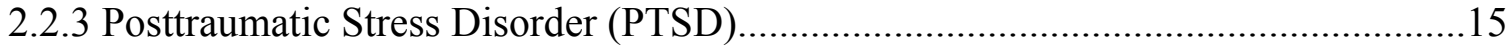

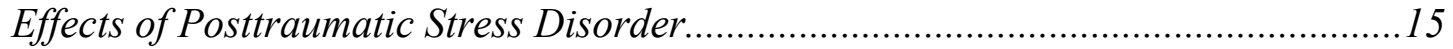

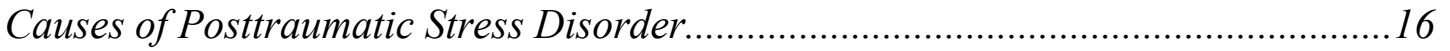

Symptoms of Posttraumatic Stress Disorder....................................................... 17

Failure to Treat Posttraumatic Stress Disorder.................................................... 18

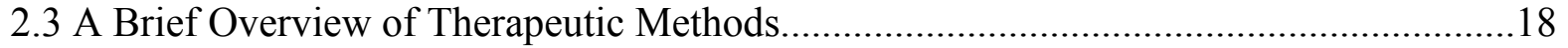

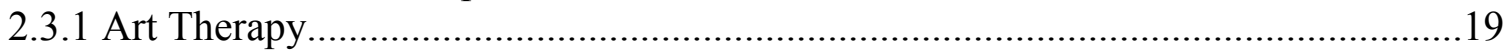

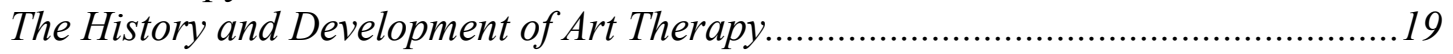

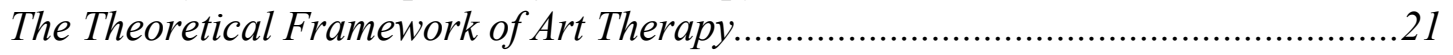

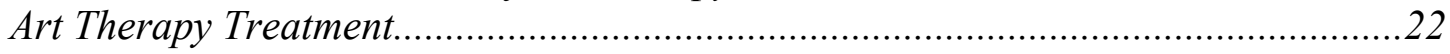

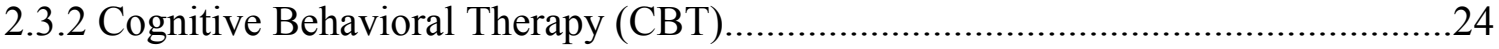

The History and Development of Cognitive Behavioral Therapy.............................24

The Theoretical Framework of Cognitive Behavioral Therapy.................................25

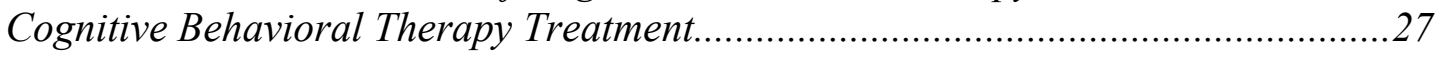

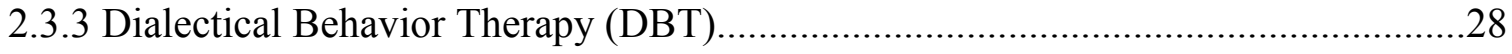

The History and Development of Dialectical Behavior Therapy..............................28

The Theoretical Framework of Dialectical Behavior Therapy...............................29

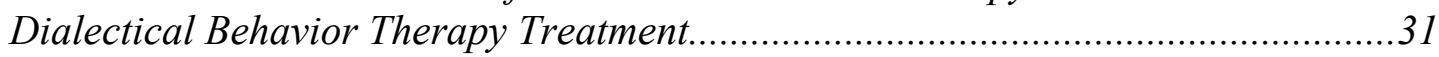

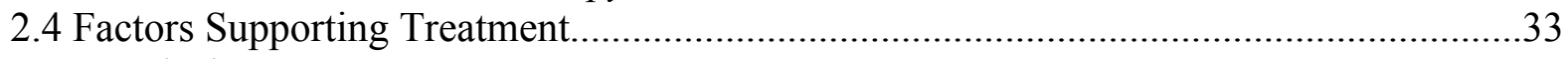

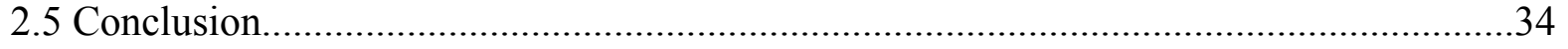

\section{CHAPTER 3- Methodology}




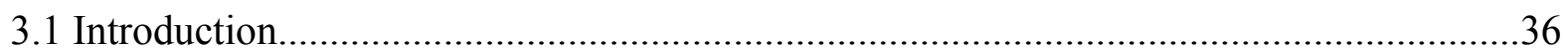

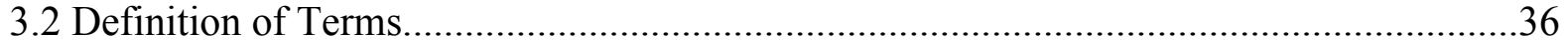

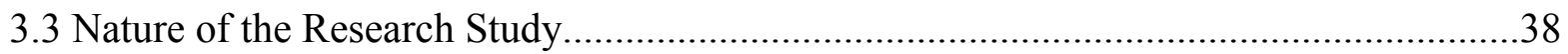

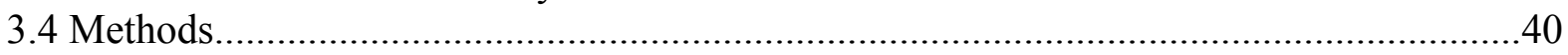

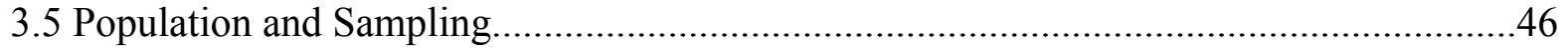

3.6 Limitations of the Study ..............................................................................................

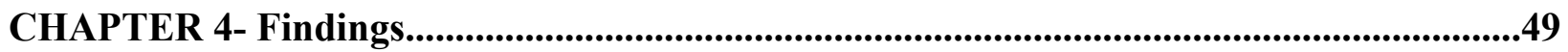

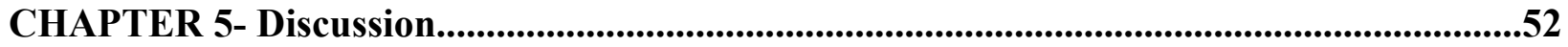

REFERENCES

APPENDIX A- Interview Transcriptions

APPENDIX B- Email Messages

Part 1: Questions \& Answers

Part 2: Therapist's Notes on the Two Clients

Part 3: Therapist's Notes on Combining Therapeutic Methods

APENDIX C- DBT Cheat Sheet Utilized During Therapy 


\section{ACKNOWLEDGEMENTS}

I would like to express my deepest appreciation to my research advisor, Dr. Terese Giobbia. Without her immense passion, expertise, support, and guidance this research project would not have been possible. In addition, I would like thank my other two research committee members, Dr. Matthew Campbell and Prof. Joseph Lupo. Their guidance and assistance helped lead the way towards the project's completion. I also would like to recognize my family for their enormous support throughout this time. Lastly, I would like to thank the therapist that allowed me to research and study her methods of treatment for children impaired by these various anxiety disorders. Without her valuable feedback and discussions, this research study would not be what it is today. 


\section{CHAPTER ONE}

\section{Introduction}

\subsection{Study Topic}

The purpose of this research was to explore how cognitive behavioral therapy (CBT) and dialectical behavior therapy (DBT) could supplement art therapy in treating children with a variety of anxiety disorders - i.e. children impaired by generalized anxiety disorder (GAD), obsessive-compulsive disorder (OCD), and posttraumatic stress disorder (PTSD). The current literature and information pertaining to art therapy, CBT, and DBT treatments for children impaired by these anxiety disorders was examined and implications for treatment of each considered.

The researcher created an exploratory case study, through the utilization of a pilot study, to investigate one therapist's collaborative therapeutic model of art therapy, CBT, and DBT methods for two children impaired by a variety of anxiety disorders - i.e. specifically GAD, OCD, and PTSD. The therapist participated in the pilot study during which interviews, emails, observations, and other forms of data were acquired. The therapist analyzed how she sees the collaborative therapeutic model—consisting of art therapy, CBT, and DBT — assisting the children impaired by these anxiety disorders, which provided this research with valuable feedback and implications for future use in treating these childhood anxiety disorders.

When the researcher initially designed this study, the researcher first wondered how children impaired by a variety of anxiety disorders might respond to art therapy as a method of treatment. However, once the researcher met with the art therapist whom the researcher was corresponding with, the design of the research shifted. The new design of the research was to study the different methods the therapist utilized instead of only focusing on the effects art 
therapy had on the treatment of the childhood anxiety disorders. The new research question that formulated this study was:

- How can one therapist supplement art therapy with cognitive behavioral therapy (CBT) and dialectical behavior therapy (DBT) during treatment of children impaired by generalized anxiety disorder (GAD), obsessive-compulsive disorder (OCD), and posttraumatic stress disorder (PTSD)?

The follow-up questions that furthered the study were:

- What art therapy, CBT, and DBT activities would be included in the collaborative therapeutic model consisting of these three therapeutic methods?

- Could other factors support treatment effectiveness during the utilization of this collaborative therapeutic model?

- How can combining these three therapeutic methods together into a collaborative model provide for a more effective treatment that is necessary to reduce the symptoms of these childhood anxiety disorders and improve their quality of life?

\subsection{Significance of Study}

This study topic is significant since children impaired by anxiety disorders are largely left untreated. Anxiety disorders continue to affect vast amounts of children and will continue to affect others in the future. Anxiety disorders can have far reaching and long-lasting effects on the cognitive and emotional development in children, as well as their overall quality of life. Art therapy, cognitive behavioral therapy (CBT), and dialectical behavior therapy (DBT) have been demonstrated to be effective in reducing the impact of anxiety disorders in children. However, 
due to the lack of research, it is imperative to further the understanding of how creating a collaborative therapeutic model of these three methods may benefit children with these disorders.

This study topic is important to me, not only because of a previous experience I had as a young child [resulting in PTSD symptoms], but also because I am an art educator who desires a further understanding of different approaches that may benefit my students in the future. After gaining the education I have from the Art Education and Art Therapy Certification programs at West Virginia University, I realized that art therapy methods are extremely versatile and compatible with other forms of therapy — specifically with the goals of providing mental health services to children exhibiting signs of cognitive and behavioral impairments. Thus, I wanted to explore the different therapeutic methods that could supplement art therapy methods in treating children exhibiting symptoms of various anxiety disorders.

With the conclusion of this research, I anticipate developing a better understanding of how art therapy, CBT, and DBT methods can support one another in the treatment of various childhood anxiety disorders. This research may lead to further exploration of the effects of childhood anxiety disorders and the efficacy of supplementing art therapy with CBT and DBT as a treatment model. It is the goal of this research study to provide three therapeutic methods that can support one another during therapy sessions to aide in reducing the symptoms and improving the quality of life in children effected by generalized anxiety disorders, obsessive-compulsive disorders, and posttraumatic stress disorders.

\subsection{Relevance of the Study Topic}

Anxiety is something that most everyone will experience at some point in their lives. It can be caused from a variety of things, including the stress of work or school, and is usually 
accompanied by a feeling of worry or fear. Per the National Institute of Mental Health (NIMH) (2016a), this occasional anxiety is normal for everyone to feel during their lives. However, repetitive anxiety or anxiety that does not go away can be a sign of an anxiety disorder (Definition section).

Anxiety disorders are one of the most common types of psychiatric disorders effecting children and adolescents today. In one study done of 10,123 adolescents aged 13-18 in the United States, nearly one in three adolescents exhibited the signs of an anxiety disorder (Merikangas, K.R., et al, 2010, p.4; Piacentini \& Roblek, 2002, p.149). Unfortunately, these childhood anxiety disorders are often left unnoticed and untreated which can cause an interference with daily activities, "such as job performance, school work, and relationships" (NIMH, 2016a, Definition section).

Several treatment modalities have been utilized with childhood anxiety disorders. Many of the treatment protocols address the possible effects anxiety disorders may have on children. Some of the treatment protocols that have been shown to be effective include art therapy, cognitive behavior therapy (CBT), and dialectical behavior therapy (DBT) (Rubin, 2010; Piacentini \& Roblek, 2002; Ritschel, Lim, \& Stewart, 2015).

Rubin (2010) lists several reasons art therapy is beneficial to people who utilize it, including the fact that art involves the whole body, art provides a nonverbal form of communication, art is flexible and versatile, and art normalizes psychotherapy. First, Rubin (2010) states that "the art process offers one of the few ways we human beings have found to utilize and to synthesize all of ourselves — body, mind, and spirit" (p.85). Producing art already involves the body, but using art as a therapeutic method also involves the mind and spirit. 
Furthermore, she suggests that art-making can promote psychological growth due to the interaction of the right and left hemispheres of the brain. Secondly, art therapy can be used as a nonverbal form of communication for children who experience difficulty discussing painful experiences. Art therapy can help these individuals express, see, and accept traumatic memories. Thirdly, she notes that art's remarkable versatility allows for any age, and almost any disability, to benefit from its therapeutic abilities. Therefore, art therapy can provide cognitive and emotional growth, as well as another form of communication, to children impaired with anxiety disorders.

Research has also lent large amounts of information regarding the treatment of anxiety disorders using CBT and DBT methods. According to Bayles \& Villalobos (2015),

CBT is the most common and effective form of psychotherapy that is used when treating individuals, such as adolescents with mental disorders and substance abuse...It allows the adolescent to alter their feelings and behaviors by exploring their past so that they can fully understand how it affects their current situation. (p. 24)

DBT was built on the foundations of CBT and "teaches skills to cope with stress, regulate emotions, and improve relationships with others" (Bayles \& Villalobos, 2015). Thus, CBT and DBT methods are also proven to assist in treatment of childhood anxiety disorders.

\subsection{Problem Statement}

The issue is that, more often than not, these children's anxiety disorders are overlooked and left untreated. This is a problem in and of itself for multiple reasons. For one, childhood anxiety disorders usually start during a child's earlier years and can progress up into the adult years of their lives. Furthermore, children with anxiety often acquire other psychiatric problems 
such as depression, behavior disorders, and substance abuse (Piacentini, J., \& Roblek, T., 2002, p. 149). Lastly, the feelings experienced in result of anxiety disorders can cause an interference with daily activities "such as job performance, school work, and relationships" (NIMH, 2016a, Definition section). Therefore, anxiety disorders have long-lasting side effects that may affect the cognitive and behavioral development in children, as well as their overall quality of life. For this reason, it is imperative that treatment for childhood anxiety disorders be efficiently and adequately treated.

One can state that the number of experimental researches on the impact and treatment of childhood anxiety disorders are still limited. Studies have shown that art therapy, CBT, and DBT appear to be effective when working with children (Rubin, 2010; Piacentini \& Roblek, 2002; Ritschel et al., 2015), but there are still limited studies on utilizing this collaborative therapeutic model. Racco \& Vis (2015) suggest that "art therapy may offer a holistic and adaptable adjacent to evidence based treatment [CBT and DBT] for children and youth," and that they may address "all affected functioning domains of children and youth" (p.127). This may be particularly true for the children studied in this research whose cognitive, emotional, and behavioral domain functions are impaired as a result of their anxiety disorders. 


\section{CHAPTER TWO}

\section{Literature Review}

\subsection{Introduction}

This study, as proposed in the first chapter, aimed to explore how cognitive behavioral therapy (CBT) and dialectical behavior therapy (DBT) can supplement art therapy in treating children with GAD, OCD, and PTSD. After defining and reviewing the anxiety disorders studied in my research, i.e. generalized anxiety disorder (GAD), obsessive-compulsive disorder (OCD), and posttraumatic stress disorder (PTSD), this chapter will initially examine the past literature of art therapy, CBT, and DBT approaches. However, since each therapeutic method has referred to the significance of their effects on children with various anxiety disorders, these theories, hypotheses, and limitations of research will also be revisited in this chapter. Also included will be the major factors that can support a child's progress during these therapeutic sessions. Finally, after critical exploration of the previous literature on these three therapeutic methods, the gaps will be identified and discussed in the conclusion.

\subsection{A Brief Overview of Childhood Anxiety Disorders}

There are many different forms of anxiety disorders. However, in accordance with this research, the discussion will be based around childhood generalized anxiety disorder (GAD), obsessive-compulsive disorder (OCD), and posttraumatic stress disorder (PTSD). In the next few sections, the definitions, effects, causes, symptoms, and the risks of failure to treat each anxiety disorder will be discussed. 


\subsubsection{Generalized Anxiety Disorder (GAD)}

Generalized anxiety disorder (GAD) is one of the main forms anxiety can take. It is much different from a normal feeling of anxiety that people can occasionally face. People with generalized anxiety disorder report excessive worrying for months at a time while also exhibiting multiple symptoms related to anxiety that interfere with their normal lives (NIMH, 2016a, Generalized Anxiety Disorder section).

\section{Effects of Generalized Anxiety Disorder}

First, it is crucial to realize the importance of the developmental stages a child goes through during their life and how anything can affect this process. Kostyunina \& DrozdikovaZaripova (2016) point out the following:

School age is appropriate for the formation of the ruling motives of personal development, skills of self-control, self-organization and self-regulation, the assimilation of social norms of behavior, development of communicative skills to socialize with peers and adults. However, if the pupil has anxiety, he becomes insecure, doubtful, impulsive, or conversely closed. (p.1105)

Furthermore, this anxiety disorder can hinder an adolescent's interpersonal interaction and social intelligence. This can greatly impact and adolescent's ability to form appropriate relationships with others. "They [adolescents with anxiety disorders] have difficulties in communication, rarely take the initiative, they have lowered learning motivation, and their behavior is close to neurotic, with obvious signs of maladaptation" (Kostyunina \& Drozdikova-Zaripova, 2016, p.1106). This theory was proven in the study conducted by Kostyunina \&Drozdikova-Zaripova (2016) in which their research studied the cause and impact of adolescents impaired by anxiety 
disorders - i.e. social anxiety disorders, in particular. They found that the adolescents had fear of self-expression, emotional stress, difficulty communicating and responding to teachers/peers, and were afraid of being misunderstood (Kostyunina \& Drozdikova-Zaripova, 2016, p.1111).

\section{Causes of Generalized Anxiety Disorder}

In order to understand and treat this disorder [GAD], we must first acknowledge the causes of GAD. Kostyunina \& Drozdikova-Zaripova (2016) state that, “Anxiety is the consequence of adolescent crisis, which flows differently and disorganizes the adolescents' personality, affecting all aspects of their life" (p.1107). Further research has provided that genetic and environmental factors can greatly increase the possibility of acquiring GAD. NIMH (2016a) include these specific factors that increase risk of contracting GAD: behavioral inhibition in childhood, being a female, having few economic resources, exposure to stressful life events in childhood, anxiety disorders in close biological relatives, parental history of mental disorders, and elevated afternoon cortisol levels in the saliva (Risk Factors section).

Piacentini \& Roblek (2002) comment that children exposed to anxious parents may cause the child themselves to contract a form of anxiety disorder. This may be caused from styles of interaction, "including overprotection and excessive control” (Piacentini \& Roblek, 2002, p.149). This again supports the statement that GAD can be caused by outside environmental factors.

\section{Symptoms of Generalized Anxiety Disorder}

Anxiety can occur as either an emotional state or as a personality trait of temperament. Kostyunina \& Drozdikova-Zaripova (2016) explain that, "anxiety is expressed in a constant sense of threat to one's own self in any situation; anxiety is a tendency to experience anxiety, 
characterized by a low threshold of occurrence of anxiety reactions which is one of the basic parameters of personality" (p.1106). Anxiety can occur as an emotional state and as a personality trait of temperament, and there is a difference between the two. Normal, occasional anxiety would be influenced by a child's emotional state, whereas GAD and other anxiety disorders would be influenced by the personality trait of temperament. Therefore, this form of anxiety effects a child's personality which can manifest itself in a variety of ways.

Piacentini \& Roblek (2002) point out that, "because childhood fears and worries are variable, the assessment of an anxiety disorder in childhood requires paying attention to developmental, cognitive, socioemotional, and biological factors" (p.150). NIMH (2016a) lists several GAD symptoms to watch for in children, including but not limited to: restlessness, being easily fatigued, difficulty concentration, difficulty of having a clear mind, irritability, muscle tension, uncontrollable worrying, and sleeping problems (insomnia) (Generalized Anxiety Disorder section). One child may manifest his/her symptoms differently than another child, but these are some of the main symptoms presented in GAD.

\section{Failure to Treat Generalized Anxiety Disorder}

Unfortunately, most children with GAD and other anxiety disorders do not receive the treatment they need to live a normal life. Piacentini \& Roblek (2002) claim that, "although effective psychosocial and drug therapy exists, these anxious youngsters are virtually ignored compared with children with other psychiatric problems" (p.149). Why is something that interferes with someone's life, as much as GAD does, so overlooked by doctors and other physicians? One of the reasons Piacentini \& Roblek (2002, p.149) suggest is that anxiety is such a normal experience for children and adults alike that it is quite often overlooked as a real 
disorder. Children and adolescents especially experience stress and anxiety while growing up and going through the educational system. Therefore, doctors term these feelings as normal fears, phobias, and anxieties.

If GAD is left untreated, the symptoms manifested by this disorder may hinder the development of a child's cognitive and emotional growth. This may entail issues with school, family, and other social situations. Also, as previously stated, these problems can carry into adulthood if left untreated. When discussing the long-term effects of anxiety disorders Piacentini \& Roblek (2002) state that, "they are associated with an increased risk of failure in school, and in adulthood, low-paying jobs and financial dependence on welfare or other government subsidies" (p.149). Therefore, it is quite evident that early intervention, a diagnosis from a doctor, and treatment are of great importance.

\subsubsection{Obsessive-Compulsive Disorder (OCD)}

Obsessive-compulsive disorder (OCD) is another common, long-lasting type of anxiety disorder. According to the National Alliance of Mental Illness (NAMI) (n.d.b), OCD is "characterized by repetitive, unwanted, intrusive thoughts (obsessions) and irrational, excessive urges to do certain actions (compulsions)" (Obsessive-Compulsive Disorder section). The person exhibiting this disorder usually understands that these thoughts and behaviors are irrational but still cannot control them. Furthermore, more than $2 \%$ of the U.S. population will be diagnosed with OCD at one time or another during their lives. That's around 1 in 40 people (NAMI, n.d.b, Obsessive-Compulsive Disorder section). Upon reviewing past literature pertaining to OCD, there was a lot of research about the adults effected by this disorder. However, within the past 25 
years, there has been a substantial amount of literature written on the OCD effecting children as well (Geller, 2006, p.353).

\section{Effects of Obsessive-Compulsive Disorder}

OCD is an anxiety disorder that may inherently effect a child's life. Stewart et al. (2004) suggest the following:

the morbid dysfunction caused by OCD that begins in youth may interfere with the trajectory of normal development at a critical period of a young person's life, impeding the consolidation of tasks such as identity and personality formation, social and educational mastery, and future orientation. (p.5)

Therefore, OCD can adversely affect a child's social skills and create a sense, or desire, of isolation. Per Stewart et al. (2004), studies have provided an outlook on education in the fact that OCD does not hinder the children's educational achievement, resulting in most children affected by OCD attending college.

\section{Causes of Obsessive-Compulsive Disorder}

The causes of OCD are still not exactly known today. However, there are three circumstances that are thought to cause OCD, including genetics, brain structuring, and environment. Genetics is a big factor that comes into play when discussing the causes of OCD. According to NIMH (2016b), studies have reported that people with first-degree relatives have a higher chance of contracting this anxiety disorder (Risk Factors in Genetics section). More specifically, there is a $25 \%$ chance that the immediate family member with contract OCD (NAMI, n.d.b, Causes section). 
Brain structure and functioning is also a factor that is thought to influence the development of OCD. "Imaging studies have shown differences in the frontal cortex and subcortical structures of the brain in patients with OCD” (NIMH, 2016b, Brain Structuring and Functioning section). Many researchers believe that these portions of the brain may not be responding correctly to serotonin. Serotonin's sole purpose is to help nerves communicate with one another, and OCD is thought to disrupt this (NAMI, n.d.b, Causes section).

Lastly, environmental factors are said to play a role in the development of OCD. NIMH (2016b) points out that children who have experienced a form of abuse or trauma are more likely to contract this anxiety disorder (Environment section). Within the environment factor is a controversial topic of Pediatric Autoimmune Neuropsychiatric Disorders Associated with Streptococcus (PANDAS). A strain of the streptococcal infection is thought to be a precipitant for developing OCD or OCD symptoms (NIMH, 2016b, Environment section). More research on the development of OCD as a result of PANDAS is needed, however. All three of these circumstances are thought to put children more at risk of developing OCD, but more research is needed to understand the actual causes of this anxiety disorder.

\section{Symptoms of Obsessive-Compulsive Disorder}

As previously mentioned, OCD is characterized by the presence of abnormal obsessions and compulsions. NAMI (n.d.b, Symptoms section) states that obsessions "are intrusive, irrational thoughts or impulses that repeatedly occur" and cause anxiety for the effected person. Whereas, compulsions "are repetitive acts that temporarily relieve the stress brought on by an obsession” (NAMI, n.d.b, Symptoms section). Each person affected by OCD experiences different kinds of obsessions and compulsions, but there are more common examples than others. 
Some common forms of obsessions include, but not limited to, fear of contamination, forbidden thoughts (involving sex, religion, and harm), aggressive thoughts, desiring a perfect order in different things (NIMH, 2016b, Signs and Symptoms section). Per Mancuso et al. (2010, p.300), children with OCD have been reported to have high rates of aggressive/harm obsessions. These aggressive obsessions include children having a fear of death or illness in themselves or a loved one. Common compulsions include, but are not limited to, excessive cleaning, arranging things in a precise manner, repetition of checking things, and compulsive counting (NIMH, 2016b, Signs and Symptoms section).

Almost everyone experiences an occasional obsession or a compulsive behavior in their lifetime, but the obsessive-compulsive symptoms that last more than an hour and interfere with daily life point to having this anxiety disorder (NAMI, n.d.b, Symptoms section). Accordingly, the symptoms manifested in OCD may also come and go or worsen over time (NIMH, 2016b, Signs and Symptoms section).

\section{Failure to Treat Obsessive-Compulsive Disorder}

According to Mancuso et al. (2010), multiple epidemiological studies of OCD have reported that most adolescents exhibiting symptoms of OCD had never been diagnosed or treated for this anxiety disorder (p.299). As mentioned before, this disorder can interfere with daily life routines, especially if the child is left untreated. Stewart et al. (2004, p.7) discuss how different studies have shown the effects of pediatric OCD, as well as the long-term effects it may have on an individual if left untreated. The studies showed high levels of unemployment (45\%) and difficulties sustaining a job (20\%) individuals impaired by OCD. 
Because most victims of OCD have never been diagnosed or treated, they may not realize their obsessive and compulsive behaviors are unordinary. Consequently, these children and adolescents impaired with this anxiety disorder may try to subside their symptoms on their own by "avoiding situations that trigger their obsessions, or they may use alcohol or drugs to calm themselves" (NIMH, 2016b, Signs and Symptoms section). This only creates more issues for the child. Therefore, it is of great importance that a child or adolescent exhibiting the symptoms of OCD seek help from a doctor or mental health provider before the symptoms interfere with their lives any further.

\subsubsection{Posttraumatic Stress Disorder (PTSD)}

Posttraumatic stress disorder (PTSD) is yet another common type of anxiety disorder that has been known to impair many children. Children impaired by this anxiety disorder have witnessed or experienced something traumatic in which the body feels a threat to life. Most people who experience traumatic situations are able to recover from the symptoms that follow.

However, other people may have a more difficult time doing so. "Following traumatic exposure, some children and youth experience psychological, physical, and emotional consequences, referred to as posttraumatic stress disorder (PTSD)" (Racco \& Vis, 2015, p.121).

\section{Effects of Posttraumatic Stress Disorder}

As previously mentioned, not all children who are exposed to traumatic experiences develop issues such as PTSD. However, Racco \& Vis (2015) note that "many experience significant adverse effects that impede their cognitive, physical, psychological, affective, interpersonal, and behavioural functioning" (p.121). Consequently, these adverse effects can also 
cause developmental regressions, dysregulation of sleep and appetite, and social constrictions.

Furthermore, a child impaired by PTSD may re-experience the scenario that had initially caused the trauma. Re-experiencing these traumatic events affects multiple functioning domains, including the suppression of emotional control and expression (Racco \& Vis, 2015, p.122).

\section{Causes of Posttraumatic Stress Disorder}

PTSD has the possibility of developing in children that experience something traumatic in their lives. In order to comprehend the causes of PTSD, there must be an understanding of what traumatic experiences may entail. Racco \& Vis (2015) note that traumatic events can "vary from single events, such as natural disasters to repetitive interpersonal violence, such as sexual abuse" (p.121). In essence, a traumatic experience is something that causes a biological response in our bodies that is known as a "fight-or-flight" response. This is a natural, bodily response that is meant to protect our bodies from harmful situations (NIMH, 2016c, Definition section).

Unfortunately, sometimes this biological response leaves several ongoing psychological symptoms "because they are not integrated into consciousness" (NAMI, n.d.b).

According to Mills \& Kellington (2012, p.3), traumatic memories and the function of the "fight-or-flight" response are often located in the amygdala portion of the brain. Normally, the brain is able to take these traumatic memories out of the amygdala and process them in the hypothalamus portion of the brain. However, Mills \& Kellington (2012, p.3) found that a person impaired by PTSD resulted in the "trauma staying in the amygdala and flooding it" (as cited in Green, 2003).

Understanding the causes of re-experiencing the traumatic experience is also a circumstance of significance when discussing the development of PTSD. When a child re- 
experiences a traumatic event, "the brain structure responsible for intense emotions is activated and brain structures responsible for emotion regulation and communication are deactivated. Therefore, re-experiencing elevates emotional reactions and suppresses emotional control and expression" (Racco \& Vis, 2015, p.122). This symptom is quite infelicitous for children, because this reaction to PTSD can hinder their brain's development and make it very difficult to achieve a normal function again.

\section{Symptoms of Posttraumatic Stress Disorder}

The different types of trauma, the time the trauma occurs in a child's life, and the duration of the trauma may all affect the development and symptoms of PTSD (Najjar, Weller, Weisbrot, \& Weller, 2008, p.105). Furthermore, young children may have difficulty interpreting, linguistically expressing themselves, and organizing their traumatic memories. This complicates the process of identifying PTSD in the child (Racco \& Vis, 2015, p.122).

Per NIMH (2016c,), the symptoms of PTSD usually manifest themselves within three months of the traumatic event. In some circumstances, however, PTSD symptoms may manifest themselves year after the traumatic experience (Signs and Symptoms section). The main three symptoms that occur from PTSD include re-experiencing the trauma, avoidance of stimuli associated with the trauma, and persistent symptoms of increased arousal (Najjar, et al., 2008, p.104).

Re-experiencing symptoms may include flashbacks (reliving the trauma), bad dreams, and frightening thoughts. "Words, objects, or situations that are reminders of the event can also trigger re-experiencing symptoms" (NIMH, 2016c, Re-experiencing symptoms section). Avoidance symptoms may include staying away from places or objects that remind the child of 
the traumatic experience (NAMI, n.d.b, Symptoms section). This may cause people to change their daily routines in order to avoid the specific situations that can trigger their PTSD. Lastly, arousal symptoms may include being easily startled, feeling tense, feeling angry, and having trouble sleeping. These symptoms manifest themselves constantly rather than needing to be triggered like the other two main symptoms (NIMH, 2016c, Arousal and reactivity symptoms section).

\section{Failure to Treat Posttraumatic Stress Disorder}

Identification of PTSD symptoms in children can be a difficult process, making access to treatment difficult. However, Racco \& Vis (2015, p.122) state that if PTSD is left untreated, the "trauma exposed youth have been found to experience co-occurring psychiatric problems such as mood disorders, anxiety disorders, and eating disorders" (as cited in Spinazzola, Rhodes, Emerson, Earle, \& Monroe, 2011). In the event that the child does happen to develop another disorder due to failure of PTSD treatment, Harned et al. (2008) note that these children are more likely to engage in acts of self-harm or suicidal attempts (p.1068). For these reasons, it is of great significance to seek help treatment from a doctor before it interferes in the child's life any further and follows the child into adulthood.

\subsection{A Brief Overview of Therapeutic Methods}

The main focus of this research study will be directed towards three different therapeutic methods, including art therapy, cognitive behavioral therapy (CBT), and dialectical behavior therapy (DBT). Within the subsequent sections, the following information concerning each therapeutic method with be examined: the definition, history and development, theoretical 
framework, and therapeutic approach of treatment (pertaining to the three, previously discussed, childhood anxiety disorders). Lastly, the limitations and gaps in the research relating to art therapy, CBT, and DBT will be examined.

\subsubsection{Art Therapy}

Art therapy, as defined by the American Art Therapy Association (AATA) (n.d.), is as follows:

a mental health profession in which clients, facilitated by the art therapist, use art media, the creative process, and the resulting artwork to explore their feelings, reconcile emotional conflicts, foster self-awareness, manage behavior and addictions, develop social skills, improve reality orientation, reduce anxiety, and increase self-esteem. (What is art therapy? section, para. 1)

Furthermore, AATA (n.d.) states that the goal of art therapy is to improve or restore an individual's sense of personal well-being (What is art therapy? section, para. 1).

\section{The History and Development of Art Therapy}

Despite the idea that art is a relatively new therapeutic approach, using art in the sense of therapy has been around for centuries. Rubin (2010) believes that the origin of art therapy lies in the natural world (p.50). She notes that there are several historical instances of art that preceded the modern development of art therapy, including: prehistoric drawings on cave walls, carved fertility figures, Egyptian paintings on mummy cases to symbolize protection, Tibetan Buddhist creators of sand mandalas, ritual masks in Africa, Byzantine painters of sacred icons, and Zuni carvers of magic fetishes (2010, p.50). Hoffmann (2016) gives further examples from Aristotle's 
concept of catharsis, in which tragedy liberated pity and fear through the use of artistic poetry (p.198). Following these prehistoric concepts lies the idea that the source of art therapy is a part of the human condition itself (Rubin, 2010, p.50).

During the late $19^{\text {th }}$ and early $20^{\text {th }}$ centuries, the concept of art therapy began to grow due to an emerging fascination in the unconscious of the human mind. "Psychiatrists found that the art images created by their patients could be used as diagnostic revelations of the unconscious which they claimed manifested visually deep portions of the human personality" (Junge, 2010, p.6). Rubin (2010, p.57-58) notes that two women paved the road for the profession of art therapy soon after this influx of psychodynamic thinking.

These two women, Margaret Naumburg and Edith Kramer, were well versed in analytic theory, child development, art, and education. Although both women based their art therapy approaches on Freud's theory of psychoanalysis, Rubin (2010, p.58) continues by acknowledging their two different definitions of art therapy. Naumburg stressed the therapy portion in art therapy, whereas, Kramer stressed the process of art portion in art therapy. These two definitions have always been, and will always be, a controversial topic in art therapy due to the many kinds of therapeutic approaches an art therapist may apply in their work.

These two women, among other art therapy pioneers, began sharing their knowledge on the what they each thought the concepts of art therapy should be. Among those pioneers was a woman named Myra Levick. Junge (2010) points out that Levick's founding of the American Art Therapy Association (AATA) greatly impacted the development of art therapy in American. Furthermore, "the establishment of the American Art Therapy Association is quite possibly the seminal event in the history of the field" (Junge, 2010, p.94). AATA allows art therapists from around the United States to spread their vast, growing knowledge in the profession of art therapy. 
"Today art therapy is widely practiced in a wide variety of settings including hospitals, psychiatric and rehabilitation facilities, wellness centers, forensic institutions, schools, crisis centers, senior communities, private practice, and other clinical and community settings" (AATA, n.d., What is art therapy? section, para. 2).

\section{The Theoretical Framework of Art Therapy}

There are multiple perspectives through which the shape of a theoretical framework formed in art therapy. However, there are three major approaches in which Rubin (2010) makes note of that this research will specifically focus on. These perspectives include psychodynamic approaches, humanistic approaches, and psycho-education approaches.

As previously noted, there was a growing interest in the field of psychoanalysis during the late $19^{\text {th }}$ and early $20^{\text {th }}$ centuries. Even though "psychoanalysis is only one of many ways trying to understand how and why people function as they do" (Rubin, 2010, p.96), art therapy and many other therapeutic approaches are rooted in this theoretical concept. Rubin (2010) continues by stating that Freudian Psychoanalysis and Jungian Analytical Psychology are both labeled as "psychodynamic because they assume that unresolved issues cause unconscious conflict, exerting tremendous power and resulting in painful symptoms" (p.96). As a result, art is used as a bypassing defense to uncover those conflicts hiding in the unconscious mind.

Humanistic approaches to art therapy were also developed in response to the new interest in the field of study known as psychoanalysis. Rubin (2010, p.100) states that humanistic approaches "emphasize the acceptance and development of individuals in the present". She continues by commenting that this approach offers a wellness model of change emphasizing selfactualization. This provides the individual with a sense of fulfillment within his or her talents and 
potentialities (2010, p.100). “All humanistic approaches emphasize man’s capacity to take charge of his life, to use free will and to exercise intentionality" (Rubin, 2010, p.103).

Lastly, Rubin (2010) notes that the psycho-education approaches in art therapy focus on behavior, cognitive, developmental, and adaptive therapies. Behavioral therapies have helped with the understanding that if something good is done, it is rewarded. Whereas, if something bad is done, the individual will be ignored or punished. This would inherently result in the dissipation of the bad behavior. Cognitive therapies "focus on habitual distorted thought processes, which are thought to underlie maladaptive feelings and behaviors" (Rubin, 2010, p.104). This approach focuses on teaching the individual to recognize the thoughts that are causing the behavioral issues and then finding new, more appropriate ways, to react to those thoughts. Developmental approaches use art to gain an understanding of growth itself. This is used a lot with children exhibiting physical and developmental disabilities (Rubin, 2010, p.107). The adaptive approach focuses on achieving specific goals that will lead to a better functioning lifestyle.

While there are many approaches in art therapy that may shape a theoretical framework for this field of profession, Rubin (2010) clarifies that “the majority of art therapists don't think of themselves as following any particular theoretical framework" (p.117). Art therapists, essentially, base their methods on the kinds of approaches they have been taught, personal preference, and what the clients need at the time of their sessions.

\section{Art Therapy Treatment}

According to AATA (n.d.), "art therapy helps people resolve conflicts, improve interpersonal skills, manage problematic behaviors, reduce negative stress, and achieve personal 
insight" (Who benefits from art therapy? section). In essence, art therapy is a form of nonverbal communication that may release stress and other feelings they may be buried deep inside.

When discussing art therapy in treatment of childhood PTSD, Racco \& Vis (2015) state that "it has been proposed that art therapy assists children exposed to traumatic events with expressing emotions and communicating their experiences, and empowers a sense of competency and control following the events" (p.126). Furthermore, Sarid \& Huss (2010) suggest that art therapy treatment for PTSD victims includes the following:

Firstly, it engages the senses and the body, through observing, touching, and manipulating art materials. Secondly, it engages autobiographical traumatic memories through the personal symbolic meanings that the client attributes to shapes, textures and colors. The art process and product becomes the symbolic container of traumatic memories. (p.9-10)

Therefore, the art activities used in art therapy treatments can "access and externalize the sensations, memories, and visual images shaped by trauma" (Kuban, 2015, p.19). Externalizing these memories, in turn, will increase coping and reduce emotional and behavioral issues that follow (Racco \& Vis, 2015).

Art therapy has also been used in treating childhood OCD. Some children exhibiting symptoms of OCD may have intrusive thoughts that are so fearsome to them that they are not able to talk about those thoughts to anyone else. However, verbalizing or expressing those fears to someone else is very important in the treatment process. Per Tippit (2016), "this is the first step in the process of helping the brain 'habituate' to the thoughts, and becoming less 'reactive' to them" (para. 3). She continues by noting that using art therapy to treat a child with OCD is about using art as a processing tool. The therapist does not interpret the art for the child, but 
instead, it is about creating something that stimulates the brain to "express, process, formulate, integrate, and possibly begin to heal" (Tippit, 2010, para. 6). Thus, art therapy methods in treatment of these various childhood anxiety disorders are thought to promote cognitive, emotional, and behavioral development. However, “art therapy's limited rigorous studies and evaluation, give rise to the need for further study" (Racco \& Vis, 2015, p.127).

\subsubsection{Cognitive Behavioral Therapy (CBT)}

According to Racco \& Vis (2015), “CBT focuses on addressing and altering dysfunctional thoughts, maladaptive behaviours and unhealthy emotional responses. It is based on the premise that one's thought about a situation or an event effects how one feels and consequently reacts or behaves" (p.124). Furthermore, "CBT is the most common and effective form of psychotherapy that is used when treating individuals, such as adolescents, with mental disorders and substance abuse" (Bayles \& Villalobos, 2015, p.24).

\section{The History and Development of Cognitive Behavioral Therapy}

Herbert \& Forman (2011) give way to the history and evolution of cognitive behavioral therapy in their research, stating that "the rise of CBT is due to the confluence of several factors, primary among which is the increased focus on evidence-based practice and associated calls for

accountability in the delivery of behavioral health services" (p.3). Hayes (2004) categorizes CBT into three waves of generations. The first wave of CBT occurred in 1950s and 1960 and was due to a perceived weakness in the constructs of psychoanalytic theory.

The approach was based on carefully delineated learning principles, many of which were developed and refined through experimental work with animals, and there were close 
connections between basic scientific developments derived from the laboratory and applied technologies. The focus was on behavior modification using techniques derived from classical and operant conditioning principles. (Herbert \& Forman, 2011, p.5)

Hayes (2004) notes that the second wave, beginning in the late 1960s and continuing into the 1990s, highlighted the "failure to provide an empirically adequate analysis of language and cognition" (p.642). Furthermore, the second stage gave behavioral principles much less emphasis and cognitive concepts were given much more emphasis. "The emphasis shifted toward exploration of the ways in which one's interpretations of the world, and especially the interpretation of emotionally relevant situations, shapes experience" (Herbert \& Forman, 2011, p.5). This focus was still one of a scientific perspective, as in the first wave.

Hayes (2004) finally discusses the third wave, beginning in the 1990s, of CBT and its shift toward the principles of acceptance and mindfulness. "Like second-generation perspectives, third-generation approaches acknowledge the importance of cognitive and verbal processes in theories of psychopathology and its treatment" (Herbert \& Forman, 2011, p.5). The difference being that the third wave generation focused on an approach that provided nonjudgmental acceptance rather than changing the client's thoughts and feelings. Furthermore, Herbert \& Forman (2011) state that "the third generation of CBT has seen a renewed interest in the field's traditional emphasis on links between basic theoretical principles and applied technologies" (p.5).

\section{The Theoretical Framework of Cognitive Behavioral Therapy}

Herbert \& Forman (2011) state that cognitive behavioral therapy (CBT) is based on two main theories that include the concepts acceptance and mindfulness. These two concepts have 
deep historical roots in psychology. The principle of acceptance has been traced to ancient Asian philosophies and Western cultures (e.g. various Hellenic philosophies, monastic Christian practices). Furthermore, topics written by Sigmund Freud discuss how "clinging to the past painful experiences precludes attention to real and immediate concerns" (Herbert \& Forman, 2011, p.7). Soon after, psychoanalysts began to follow in Freud's footsteps and set acceptance as a primary goal during psychotherapy. In the 1990s (Herbert \& Forman, 2011), there was a "gradual shift in focus from self-acceptance to the acceptance of one's ongoing subjective experience, and especially distressing experience, often referred to as psychological or 'experiential' acceptance" (p.7). This provided a framework for the acceptance of one's entire experience no matter the positive or negative emotions that followed, as well as "the willingness to abandon efforts to hold onto tightly to positive experiences" (Herbert \& Forman, 2011, p.13). The principle of mindfulness has also been tracked back to its past, historical roots. Herbert \& Forman (2011) note that: mindfulness has been traced back to the principles of Buddhist traditions. A central tenant of Buddhism is that human suffering is the result of desiring 'that which is not,' that is, an attachment to specific material objects and states of mind that cannot always be present. As all things are transient, such attachment results in suffering. (p.6) Mindfulness, provided by Kabat-Zinn, is "paying attention in a particular way: on purpose, in the present moment, and nonjudgmentally" (p.4). Therefore, mindfulness provides an avenue to being present, instead of in the past, and bringing inner peace to one's thoughts and feelings. According to Herbert \& Forman (2011), combining these two principles together creates an acceptance-based therapeutic model that places an emphasis on "changing the 
relationship between cognitions and behavior rather than change the content of the cognitions themselves" (p.14).

\section{Cognitive Behavioral Therapy Treatment}

CBT has been used during the treatment of a variety of mental health disorders due to the results showing "changes in brain activity, suggesting that this therapy actually improves your brain functioning as well" (NAMI, n.d.c, Cognitive Behavioral Therapy section). Among these mental health disorders are various childhood anxiety disorders that have been treated with CBT - e.g. GAD, OCD, and PTSD.

CBT has largely been used during the treatment of childhood GAD. CBT methods “typically address the child's illness across many dimensions, including somatic (physical complaints), cognitive (biased thinking), and behavioral (clinging, crying, avoidance) problems" (Piacentini \& Roblek, 2002, p.150). Piacentini \& Roblek (2002) continue by stating that the "results of controlled trials show that cognitive behavior therapy can be effective in as many as $70 \%$ of clinically anxious children" (p.150). This treatment is very versatile and can be used with families, groups, and schools. CBT also has a vast amount of research in regards to the treatment of PTSD in children. Najjar et al. (2008, p.106) suggest that "it addresses the core features of PTSD (i.e., re-experiencing, avoidance, and arousal)", and an "accurate account of the event is created and consequently distorted to relieve the child and to allow him or her to develop alternate cognitions". This allows the children to stop blaming themselves and stop feeling guilty about the situation that caused this traumatic anxiety disorder.

Mancuso et al. (2010) provide evidence on the treatment of childhood OCD through the utilization of CBT, stating that "when possible, cognitive behavioral therapy (CBT) is the first 
line treatment for mild to moderate cases of OCD in children” (p.301). Furthermore, Mancuso et al. (2010) suggest that CBT creates "a sense of personal efficacy, predictability, controllability, and self-attribute likelihood of appositive outcome" (p.301), which are all supportive during the treatment of OCD. Although previous literature considers CBT to be the therapy of choice when treating childhood anxiety disorders, Benjamin, Puleo, Settipani, Brodman, Edmunds, Cummings, \& Kendall (2011) state that "additional work is needed to understand the mediators, moderators, and predictors of treatment outcome, and to pursue the dissemination of efficacious CBT approaches" (p.185).

\subsubsection{Dialectical Behavior Therapy (DBT)}

Dialectical behavior therapy (DBT), a comprehensive cognitive behavioral treatment that “teaches skills to cope with stress, regulate emotions, and improve relationships with others," also "coincides with CBT because it provides a sense of calmness and allows the adolescents to regroup themselves" (Bayles \& Villalobos, 2015, p.24). Even though it is heavily based on CBT, DBT has a rather large difference because "it emphasizes validation, or accepting uncomfortable thoughts, feelings and behaviors instead of struggling with them" (NAMI, n.d.c). Per "Dialectical Behavior Therapy" (2016), this form of treatment "focuses on problem solving and acceptance-based strategies within a framework of dialectical methods" (para. 1).

\section{The History and Development of Dialectical Behavior Therapy}

In order to understand how dialectical behavior therapy (DBT) works, the history of this therapeutic method must be acknowledged. Per Linehan \& Wilks (2015), “dialectical behavior 
therapy (DBT) emerged from attempts to apply standard behavior therapy to the treatment of highly suicidal individuals" (p.97). "What is DBT?" (n.d.) summarizes this by stating:

In the late 1970s, Marsha M. Linehan attempted to apply standard Cognitive Behavior Therapy (CBT) to the problems of adult women with histories of chronic suicide attempts, suicidal ideation, and non-suicidal injury...As she and her research team applied standard CBT, they encountered numerous problems with its use. (The Development of DBT section)

Linehan \& Wilks (2015) summarizes the three problems Linehan encountered during treatment. The first problem was encountered because the treatments were mainly focused on problem-solving strategies, and "the focus on problem solving was experienced as extremely invalidating by clients...In response, treatment shifted dramatically to focus on warmth and acceptance" (p.98). However, the clients were just as equally frustrated with this treatment because they said it was not solving their problems altogether. Afterwards, the third try was initiated, which entailed an acceptance and change approach — "accepting clients where they are while pushing for progress and combining a range of change strategies aimed at problem solutions and acceptance strategies with a core emphasis on validation" (Linehan \& Wilks, 2015, p.24). However, this also failed because the pain was too intolerable for the clients while they were working on other treatment goals. This prompted a need for change in the traditional behavioral treatment.

\section{The Theoretical Framework of Dialectical Behavior Therapy}

Linehan \& Wilks (2015) give an account of the three major theories that provide a framework for DBT, including the mindfulness, biosocial, and dialectic theories. The initial 
problem was "where to find an acceptance-based practice that did not focus on change" (p.99). Acceptance-based treatments allowed for positive reinforcement that eventually resulted in change. "Thus, the basic Zen practices, along with aspects of other contemplative practices, were translated into a set of behavioral skills that could be taught to both clients and therapists" (p.99). The term that was then associated with this Zen practice was mindfulness. DBT was the first psychotherapy to utilize the concept of mindfulness as a main component ("What is DBT?", n.d.). The next problem was how to design an effective model of therapy that would not belittle the client and would be compatible with previous research findings. From this, the biosocial theory was created, "which states that BPD [Borderline Personality Disorder] is a pervasive disorder of the emotion regulation system" (p.99). Furthermore, the article "Dialectical Behavior Therapy" (2016) states that:

The theory posits that some people are born with a predisposition toward emotional vulnerability. Environments that lack solid structure and stability can intensify a person's negative emotional responses and influence patterns of interaction that become destructive. (DBT Theory section)

The last problem that needed to be encountered was to establish a theoretical framework that combined both the "principles of Zen and other contemplative practices with behaviorism" (Linehan \& Wilks, 2015, p.99). The dialects theory was established which created the notion of synthesizing oppositions - i.e. acceptance and change. "Therapists use dialects to help people accept the parts of themselves they do not like and to provide motivation and encouragement to address the change of those parts" ("Dialectical Behavior Therapy", 2016, DBT Theory section). 


\section{Dialectical Behavior Therapy Treatment}

Historically, DBT was initially linked to the treatment of BPD, but Ritschel et al. (2015) state that two factors led to the broader application of it, including:

First, individuals with BPD tend to meet criteria for at least one additional diagnosis...Moreover the empirical evidence for DBT demonstrates that the treatment is effective not only for reducing the major treatment targets of suicide and NSSI [no suicidal self-injury], but also associated psychological difficulties, such as depression and trauma symptoms. (p.112)

Thus, the treatment was spread to clients presenting a variety of disorders, including but not limited to: eating disorders substance use disorders, trauma, and depression.

For DBT to be effective for these wide range of clients, the treatment had to be principle based and very flexible. The strategies and principles that evolved from this were known as modularity and hierarchy. According to Linehan \& Wilks (2015) "modularity can be used to separate the functions of a treatment/intervention into independent modules such that each module contains everything necessary to carry out one specific aspect of the desired treatment" (p.101). This inherently allows for flexibility in changing the treatment for the patient on an as needed basis. "Hierarchy is built into the treatment by having predetermined levels of disorder, which are addressed in order from most to least severe" (Linehan \& Wilks, 2015, p.101). The priorities - from most important to least important — consist of treatment that decreases lifethreatening behaviors, therapy-interfering behaviors, quality of life behaviors, and skills acquisition (“What is DBT?”, n.d.)

According to Linehan \& Wilks (2015), DBT is broken into four stages of treatment. The first stage of DBT stabilizes the client and achieves behavioral control. Thus, the first stage 
utilizes the hierarchy of treatment because it focuses on decreasing certain behaviors the client might be exhibiting. During stage 2 (Linehan \& Wilks, 2015), the client is able to experience a full range of emotions. PTSD is normally treated during this stage because stage 2 teaches the client how to understand and process the traumatic events. The goal of stage 3 is "that the client leads a life of ordinary happiness and unhappiness" ("What is DBT?", n.d. What are the stages section). Finally, "stage 4 is designed to increase a sense of completeness, to find joy, and/or achieve transcendence" (Linehan \& Wilks, 2015, p.101).

Treatment is lastly split into two parts, which includes skill training and problem solving/motivational issues. The skills training consists of the clients learning new behaviors to replace the negative, ineffective behaviors. "Skills training is didactically focused, with heavy emphasis on skills training procedures, including modeling, instructions stories, behavioral rehearsal, feedback and coaching, and homework assignments" (Linehan \& Wilks, 2015, p.103). The four skills taught are mindfulness, interpersonal effectiveness, emotional regulation, and distress tolerance.

The article "What is DBT?" (n.d.) gives a summary of what the four skills teach the clients. Mindfulness teaches the client to become fully aware and to be present in the moment. Distress tolerance teaches the clients to tolerate pain instead of changing it. Interpersonal effectiveness teaches the clients to maintain self-respect and respect for others by learning how to ask for what they [the clients] want. Emotion regulation teaches the clients to change emotions that they want or need to change (What skills are taught section). Furthermore, Linehan \& Wilks (2015) state that "skills are separated into 'change skill' (interpersonal effectiveness and emotional regulation) and 'acceptance skills' (mindfulness and distress tolerance)" (p.103). 
In conclusion, DBT is an evidence-based treatment that "seamlessly allows the therapist to dialectically blend the essential elements of DBT (e.g., structural strategies, communication strategies) with empirically supported protocols for co-occurring diagnoses such as eating disorders, PTSD, and SUDs [substance use disorders]” (Ritschel et al., 2015, p.126). Its flexibility allows it to be successfully used across work or school settings (Linehan \& Wilks, 2015). However, DBT does offer limitations of research in multiple areas of childhood anxiety disorders, including GAD and OCD. Both disorders lend negative behaviors to the clients, which brings to question why DBT does not have more research in those areas. Further studies in these areas would need to be undertaken to find out if DBT is proven to be efficacious in those areas.

\subsection{Factors Supporting Treatment}

A child's progress during the process of art therapy, CBT, and DBT has been shown to largely depend on multiple outside factors, including family and social support and the therapist providing a safe environment by maintaining good rapport during the therapy sessions. Children not only need support from family in providing the modes of care and treatment, but they also need family and friend support in telling them that everything is going to be okay. Sisemore (2012) states that "a person with generalized anxiety who asks multiple questions about possible problems might ask her friend to gently ask her in return, 'Would it be better if I didn't answer your question?"' (p.76). This is especially true after a child experiences something traumatic. The last thing that needs to happen is for the child to feel more alone and isolated than ever due to the depression that can follow PTSD. Therefore, family and social validation of these feelings can help support a child's progress during treatment. 
The last factor that provides support during the therapeutic treatment process is rapport. Rapport refers to the close relationships among the therapist and the clients in order to understand their feelings and help the children work through them. This can only happen in a setting that feels safe and trusting for the children. Rubin (2010) states that "it could be argued that a safe and secure psychological framework for all therapy, including art therapy, is even more critical than a physical one" (p.77). Therefore, it is important to create a peaceful, safe environment for the client to gain trust in the therapist. Once good rapport is established, children are more apt to exploring their feelings and problems.

\subsection{Conclusion}

In conclusion, there is an issue with children not receiving adequate treatment for their anxiety disorders. It is imperative that childhood anxiety disorders be paid attention to, diagnosed, and treated. If left untreated, these disorders can significantly affect the child's cognitive, emotional, and behavioral development, as well as their overall quality of life. It is important to use therapeutic treatments that can treat these disorders as effectively as possible. "A child during therapeutic activities learns to manifest its own experiences, feelings, understanding and acceptance of itself and others. A child has an ability to meet needs of, among others, safety, acceptance, being understood, perceived and appreciated" (Hoffmann, 2016, p.200).

One can state that the number of experimental researches on the impact and treatment of childhood anxiety disorders are still limited. There are a lot of approaches that have been known to treat childhood anxiety disorders, including art therapy, CBT, and DBT. However, it seems that each therapeutic method offers something different for each disorder discussed-i.e. GAD, 
OCD, and PTSD. "What appears apparent is that no one model fits the needs of all children and youth from birth to 18 " (Racco \& Vis, 2015). For instance, the most common treatment for a lot of childhood anxiety disorders is CBT, but art therapy may provide another way for children to express their feelings and thoughts other than talking. Therefore, perhaps the solution would be to be to combine art therapy's holistic, flexible methods with the evidence based treatments, like CBT and DBT. There is a lack of research on supplementing art therapy with CBT and DBT during the treatment of childhood anxiety disorders, but using a collaborative model with all three of these therapeutic methods in it may ensure that "all affected functioning domains of children and youth" are effectively treated (Racco \& Vis, 2015, p.127).

In regards of treatment, no treatment method can be adequately effective without the support of the child's family and friends. The child's need for validation and comfort is exponential when dealing with an anxiety disorder that can cause isolation, depression, and guilt. Among these important factors lies the importance of the therapist maintaining a good rapport with the clients. In order for the child to feel safe and secure, the therapist must create an environment that feels as such. This in turn will create a sense of trust and closeness between the clients and the therapist. All three of these factors play a large role in the progress of treatment for these children impaired by various anxiety disorders. 


\section{CHAPTER THREE}

\section{Methodology}

\subsection{Introduction}

The focus of this chapter is the nature of the research, a description of the methods used in carrying out the study, and the research design as well as their suitability for the topic. The chapter first presents the definitions of terms that may apply to this research study. The subsequent sections include the nature of the research, the methods used, and the design of the study - i.e. the population, sampling techniques, data collection procedures, analysis, and the instruments used in the study.

\subsection{Definition of Terms}

Art Therapy: Art therapy, as defined by the American Art Therapy Association (AATA) (n.d.), is "a mental health profession in which clients, facilitated by the art therapist, use art media, the creative process, and the resulting artwork to explore their feelings, reconcile emotional conflicts, foster self-awareness, manage behavior and addictions, develop social skills, improve reality orientation, reduce anxiety, and increase selfesteem" (What is art therapy? section, para. 1).

Cognitive Behavioral Therapy (CBT): “Cognitive behavioral therapy (CBT) focuses on exploring relationships among a person's thoughts, feelings and behaviors...The core principles of CBT are identifying negative or false beliefs and testing or restructuring them" (NAMI, n.d.c, Cognitive Behavioral Therapy section).

Dialectical Behavior Therapy (DBT): "DBT is heavily based on CBT with one big 
exception: It emphasizes validation, or accepting uncomfortable thoughts, feelings and behaviors instead of struggling with them...They [the therapists] also help the person develop new skills, like coping methods and mindfulness practices, so that the person has the power to improve unhealthy thoughts and behaviors" (NAMI, n.d.c, Dialectical Behavior Therapy section).

Narrative Therapy: According to Jacobs, McCall, \& Lorig (2015) from the Chill \& Spill book, narrative therapy "asks key questions that help separate the problem from the person, allowing the retelling of events and creating a narrative of hope" (p.9).

Furthermore, Jacobs et al. (2015) states that it "decreases feelings of isolation and normalizes difficult experiences" (p.9).

Generalized Anxiety Disorder (GAD): People with generalized anxiety disorder report excessive worrying for months at a time while also exhibiting multiple symptoms related to anxiety that interfere with their normal lives (NIMH, 2016a, Generalized Anxiety Disorder section).

Obsessive-Compulsive Disorder (OCD): According to NAMI (n.d.b), OCD is "characterized by repetitive, unwanted, intrusive thoughts (obsessions) and irrational, excessive urges to do certain actions (compulsions)" (Obsessive-Compulsive Disorder section).

Posttraumatic Stress Disorder (PTSD): "Following traumatic exposure, some children and youth experience psychological, physical, and emotional consequences, referred to as posttraumatic stress disorder (PTSD)" (Racco \& Vis, 2015, p.121).

Qualitative Research: Qualitative methods allow the researcher to become "immersed in 
it [the research] and to move into the culture or organization being studied and experience what it is like to be a part of it" (Krauss, 2005, p.760). Furthermore, qualitative research allows the researcher to utilize methods, such as "observation, interviewing, ethnographic fieldwork, discourse analysis and textual analysis" (Travers, 2001, p.2). This provides the researcher the ability to generate meanings from the information studied.

Case Study: A case study "refers to the collection and presentation of detailed information about a particular participant or small group, frequently including the accounts of subjects themselves” (“Case Studies”, n.d.).

Pilot Study: A pilot study is "a small-scale test of the methods and procedures to be used on a larger scale..." (Porta \& International Epidemiological Association, 2008). Furthermore, Leon, Davis, \& Kraemer (2011) note that "a pilot study can be used to evaluate the feasibility of recruitment, randomization, retention, assessment procedures, new methods, and/or implementation of the novel intervention" (p.626).

\subsection{Nature of the Research Study}

The purpose for conducting this research was to establish how therapists can supplement art therapy with CBT and DBT during treatment of various childhood anxiety disorders. The main research question for this study was: How can one therapist supplement art therapy with cognitive behavioral therapy (CBT) and dialectical behavior therapy (DBT) during treatment of children impaired by generalized anxiety disorder (GAD), obsessive-compulsive disorder (OCD), and posttraumatic stress disorder (PTSD)? 
Other questions that guided this research were:

- What art therapy, CBT, and DBT activities would be included in the collaborative therapeutic model consisting of these three therapeutic methods?

- Could other factors support treatment effectiveness during the utilization of this collaborative therapeutic model?

- How can combining these three therapeutic methods together into a collaborative model provide for a more effective treatment that is necessary to reduce the symptoms of these childhood anxiety disorders and improve their quality of life?

Majority of researchers recommend more focus on psycho-education, skill development, and mindfulness that $\mathrm{CBT}$ and $\mathrm{DBT}$ can offer in treating these various childhood anxiety disorders, not taking into account the importance of body awareness and sensory mastery that more flexible, holistic approaches can provide - i.e. art therapy (Racco \&Vis, 2015). CBT "might limit the flexibility and interpersonal context" needed for treatment of childhood anxiety disorders, while DBT's mindfulness concept might be too complex for children and youth to grasp (Racco \& Vis, 2015, p.124,125). Racco \& Vis (2015) further observe that art therapy, although not widely researched, may provide a more holistic approach on treatment that can offer other mind/body interventions that "prove to be more hands-on, requiring less conceptualization" (p.125). Racco \& Vis (2015) conclude by noting that collaborating the treatments together could be useful in treating children exhibiting signs of anxiety disorders. The focus of this study was to explore how to utilize this collaborative model of therapy approaches. The study was conducted through a carefully designed methodology, which entailed one therapist's treatment approaches that were exclusively focused on supplementing art therapy with $\mathrm{CBT}$ and DBT during the treatment of childhood GAD, OCD, and PTSD. 


\subsection{Methods}

This study used qualitative research methods because it could provide this research with a thorough examination of the specific topic that is being understood. The qualitative research methodology utilized a theoretical approach as part of the study involving the study and analysis of the previous literature surrounding the childhood anxiety disorders and the three therapeutic treatments. The qualitative research methodology also provided a means to create an exploratory case study [by utilizing the pilot study approach], which allowed the researcher to select a sample population that would represent a defined population. In this case, one therapist and her two clients were selected to represent a population of therapists treating childhood GAD, OCD, and PTSD by using a collaboration of art therapy, CBT, and DBT methods. Results from the qualitative research were largely exploratory and descriptive. They entailed an empirical method approach during the interviewing, observing, and reporting of the sample population.

The interview and other methods of research explored multiple factors pertinent to my research, including the therapist's background of experience and the description of her employer's facility. However, for the purpose of this section, the topics that will be discussed are: the backgrounds of the two children impaired by these anxiety disorders, the processes used to treat the children, and the factors that supported the children through their therapeutic journey. Exploring these topics furthered the understanding of utilizing a collaborative therapeutic model in treating childhood GAD, OCD, and PTSD.

The first client [Client \#1] was a 10-year-old female exhibiting signs of generalized anxiety disorder (GAD) and obsessive-compulsive disorder (OCD), in which both cases were 
situational. The therapist noted that "there are certain situations where she might feel a threat. So she, might have anxiety about a specific situation, and she has to do a neutralizing event to try to make it better" (personal communication, November 1, 2016). Client \#1 exhibited fears of losing things, or that something bad would happen to her belongings, when going away on long trips. This coincided with symptoms of GAD and OCD - i.e. the act of checking on objects and the fear that a catastrophe might occur (Mancuso et al., 2010). Furthermore, when asked about the initial causes of Client \#1's anxiety disorders, the therapist noted that the child was just that way. By this the therapist meant that the child exhibited signs of these disorders because of the biosocial theory - i.e. a combination of the environment and biology. The client's mom exhibited signs of anxiety as well. Therefore, the therapist noted that "it was modeled for her and kind of a little bit ingrained in her. Probably a little bit of both" (personal communication, November 1, 2016).

After understanding Client \#1's background, the therapist was able to explain the collaborative treatments utilized during the child's therapy sessions. The therapist utilized art therapy and supplemented that with activities in CBT, DBT, and narrative therapy. The therapist noted that using CBT trained the child on "actual rationalizing, recognizing what faulty beliefs they hold about the situation, and how that reinforces the thought process that goes into it" (personal communication, November 1, 2016). The therapist suggested that coupling this with art therapy helped Client \#1 "get it [anxieties] out and to be able to show me [the therapist] what's really going on, and it also reinforces leaning on others" (Therapist, personal communication, November 1, 2016). Therefore, art therapy was used in the sense of social support. It allowed the child to understand that she does not have to feel anxious all by herself, and she could turn to someone like her mom for help. This also played into DBT because, through her mom's 
validation of the child's feelings of anxieties, the child was also able to accept and validate those thoughts (Bayles \& Villalobos, 2015). Thus, it is easy to see how utilizing the collaborative therapeutic model was able to supplement art therapy with CBT and DBT during Client \#1's therapy sessions.

The second client [Client \#2] was a 14-year-old female exhibiting signs of posttraumatic stress disorder (PTSD). The therapist noted that the child committed acts of self-harm, suicidal ideations, alcohol abuse, and aggressive behaviors (personal communication, November 1, 2016). This coincided with symptoms of PTSD — i.e. acts of angry outbursts, self-harm, suicide attempts, and substance abuse (NIMH, 2016c). Furthermore, when asked about the initial causes of Client \#2's anxiety disorder, the therapist noted that the child's PTSD was a result of a past traumatic experience (sexual assault), as well as being neglected and bullied at both home and school. The therapist also noted the possibility of drug abuse at home during the neglectful time periods (personal communication, November 1, 2016).

After understanding Client \#2's background, the therapist was able to explain the collaborative treatments utilized during the child's therapy sessions. Similar to Client \#1's treatment process, the therapist also utilized art therapy and supplemented that with activities in CBT, DBT, and narrative therapy during Client \#2's therapy sessions. The therapist noted that using CBT helped Client \#2 dissect the harmful emotions and beliefs in order to change the behaviors that resulted from them-i.e. "getting her to recognize it [the act of an aggressive outburst] was a defense mechanism she was using to make herself feel more powerful in a situation that's out of her control" (personal communication, November 1, 2016).

The therapist suggested that coupling this with art therapy and narrative therapy helped 
Client \#2's progress. "When she's really able to tell her story-her perception of it—when she's able to draw it out, when she's able to write it out, when she's able to use clay and mold stuff, when she's able to put animals to people — and why are they that animal and what does that mean - that's all about gaining personal awareness as to how she views people" (Therapist, personal communication, November 1, 2016). This played into DBT because, through the therapist's validation of the child's feelings, the child was also able to accept and validate those thoughts (Bayles \& Villalobos, 2015). DBT methods also relate to the treatment of childhood anxiety disorders paired with substance abuse (Ritschel et al., 2015). This further supported the use of DBT in Client \#2's treatment since she was also a child who abused alcohol substances. Similar to Client \#1's treatment, it is easy to see how utilizing a collaborative therapeutic model was able to supplement art therapy with CBT and DBT during Client \#2's therapy sessions.

When discussing the activities used in art therapy, CBT, and DBT methods, the therapist was able to provide further discussion and specific documentation of the descriptions. She utilized three separate books during the clients' treatments. The first was the Chill \& Spill book that was created by the Art with Heart Organization, which Jacobs et al. (2015) said provides a "guided, therapeutic journal that helps participants explore identity, goals, loss, transitions, and self-awareness through creative self-expression...It is a uniquely effective, eclectic tool that is designed to foster emotional intelligence and teach skills that youth will carry with them into adulthood" (p.11). This book utilizes a blended approach of CBT, narrative therapy, and art therapy in order to promote these skills in a structured and focused manner. The Art with Heart Organization also created the Draw It Out (n.d.) book that utilizes CBT, narrative therapy, art therapy, and social emotional learning. The therapist noted that "this curriculum prompts children to access complex emotions through creative expression, self-soothing and self-care, 
decreased feelings of isolation, ability to identify and build trusted relationships, revelation of perceptions of misconceptions, processing loss(es), and social emotional learning such as selfawareness, creative problem solving, perseverance, and effective communication" (personal communication, November 1, 2016).

Lastly, the therapist utilized the "Mixed Emotions" cards that were created by the Art with Heart Organization to "help clients identify how they feel, as each card has a primary emotion at the top and similar emotions at the bottom, with a drawing in the center related to the emotion" (Therapist, personal communication, November 1, 20016). The cards also assisted the clients in making decisions about different scenarios, identify positive and negative emotions, determine the cause of their 'emotional tidal waves', resolve conflicts in themselves as well as with others, and build emotional intimacy (Therapist, personal communication, November, 1, 2016). Understanding these activities further supported her decision to utilize them during the therapy sessions consisting of using art therapy, CBT, and DBT methods, as well as narrative therapy.

The therapist also noted several outside factors that could influence both clients during their treatment journeys, including family support, social support-e.g. extracurricular activities - and the maintaining of good rapport between the therapist and her two clients. Family support played a big role in the progression of treatment for both clients. On one hand, Client \#1 had a lot of family support. Because family supported and assisted in the validation of her thoughts and behaviors, Client \#1 was able to see rather quick improvements-i.e. less anxiety and a decrease in obsessive thoughts and behaviors (Therapist, personal communication, November 1, 2016). On the other hand, Client \#2 did not have a lot of family support. She continued to go through difficult times with her family, including neglect and bullying. This 
regretfully created a "one step forward, two steps back" sequence of events. Fortunately, the therapist still saw progress with Client \#2 even with these setbacks-i.e. improvement in cognitive and behavioral functions (Therapist, personal communication, November 1, 2016). Furthermore, the therapist mentioned having social support, e.g. involvement in extracurricular activities, was good for the clients' progresses. The importance of both family support and social support were noted in previous literature (NAMI, n.d.a; NAMI, n.d.b; Sisemore, 2012).

Lastly, the therapist discussed the importance of maintaining the concept of a good rapport between the therapist and her two clients. This referred to the therapist creating a safe environment that provided a trusting, nonjudgmental relationship between the therapist and her two clients. The therapist stated that "if you don't have [good] rapport, you could be the smartest person in the world, and they [the clients] don't care. I also feel like you could be the dumbest person in the world and, as long as they like you, they're going to listen to what you say" (personal communication, November 1, 2016). This coincided with previous literature that discussed creating a safe environment in which the clients felt comfortable enough to express their feelings and issues, which in turn created trust between the therapist and clients themselves. Rubin (2010) noted that "most art therapists work hard to create a peaceful and protected atmosphere, one where the spirit can safely soar" (p.78). Thus, it is important to create a setting where the clients feel at ease and trust the person providing the different forms of therapy.

From these research methods, the researcher was able to understand how the therapist could utilize a collaborative therapeutic model by supplementing art therapy with CBT and DBT during the treatment of childhood GAD, OCD, and PTSD. The researcher also gathered information that provided an understanding of what art therapy, CBT, and DBT activities would be included in the collaborative therapeutic model consisting of these three therapeutic methods, 
what other factors supported treatment effectiveness during the utilization of this collaborative therapeutic model, and how combining these three therapeutic methods together into a collaborative model provided for a more effective treatment that was necessary to reduce the symptoms of these childhood anxiety disorders and improve the children's overall quality of life.

\subsection{Population and Sampling}

An important element that gave authority to this research study involved the validity of the population and sample selection. Target populations included all the participants that are of theoretical interest to the study and which the researcher would like to generalize. In such a case, the target population for this study was one therapist who utilized a collaborative therapeutic model, consisting of art therapy, CBT, and DBT, to treat her two clients suffering from childhood GAD, OCD, and PTSD. Participant criterion was that the therapist is

i. Experienced in treating children impaired by GAD, OCD, and PTSD

ii. Experienced in supplementing art therapy with CBT and DBT within a collaborative therapeutic model

The therapist received her Bachelor's Degree in Speech Pathology and Audiology and her Master's Degree in Social Work. After she gained experience in the advocacy and young intervention programs, her interests in therapy grew, resulting in her obtaining an LSGW, also known as a Licensed Graduate Social Worker. Following this licensure, the therapist began working with a company that provided in-home therapy to children in school. After time spent at this business, the therapist began to work at a psychological service facility. The therapist has 
been at this facility for almost two years, and she has treated a multitude of clients exhibiting a variety of problems in all ages from young children to adults. The therapist specialized, however, in treating children and adolescents impaired by a various anxiety disorders, especially PTSD as a result of trauma. The therapist utilized a collaborative therapeutic model, which includes art therapy, CBT, and DBT, during the treatment of her clients. Art therapy intervention was paced throughout sessions, while CBT, DBT, and narrative skills were used in follow up questions to gain insight, offer feedback, and interpret the art imagery.

\subsection{Limitations of the study}

The therapist's collaborative therapeutic model, consisting of art therapy, CBT, and DBT, were given to two children with similar backgrounds. The case study client participants had similar backgrounds including similar demographics (both were female, West Virginia residents, and impaired by childhood anxiety disorders). This meant that the study did not have a control group. It would therefore be a convoluted task to draw inferences as to what was the cause of improvement or poor performance. Improvements could be construed to mean that:

i. The utilization of art therapy, DBT, and DBT within a collaborative therapeutic model provided for a more effective treatment that was necessary to reduce the symptoms of these childhood anxiety disorders and improve the children's overall quality of life

ii. The art therapy, CBT, and DBT activities included in the collaborative therapeutic model were responsible for the children's marked improvements

iii. The factors of family and social support, as well as the therapist maintaining a good 
rapport with the clients, affected the children's progression during treatment.

Either way, none of the above inferences are conclusive enough and more research needs to be done on the topic, using control groups to establish the specific impact of the collaborative therapeutic model. However, the study provided insight on how to create a collaborative therapeutic model that could supplement art therapy with CBT and DBT during the treatment of childhood GAD, OCD, and PTSD. In particular, the interviews, observations, and documents provided the researcher with insight on utilizing this collaborative therapeutic model was subsequently able to make recommendations on possible improvements that would address the treatment of specific issues in these childhood anxiety disorders. 


\section{CHAPTER FOUR}

\section{Findings}

There were definitive marked improvements in the clients' thoughts, emotions, behaviors, and overall quality of life, that resulted from utilizing a collaborative modelconsisting of art therapy, CBT, and DBT_-during treatment of their childhood anxiety disorders. The improvements in Client \#1's life included not needing excessive reassurance about feared situations, engaging in activities that would have previously caused anxiety, and improvements on obsessive-compulsive thoughts and behaviors. The improvements in Client \#2's life included gaining an understanding of events and core emotions, noninvolvement in aggressive behaviors, noninvolvement in self-harming activities, improved feelings of anxiety and depression, exhibiting respect for others, and better communication skills involving feelings.

This study has raised questions about how a therapist can supplement art therapy with CBT and DBT within a collaborative model during the treatment of childhood GAD, OCD, and PTSD. Improved results may be construed to imply:

1. The utilization of art therapy, DBT, and DBT within a collaborative therapeutic model provided for a more effective treatment that was necessary to reduce the symptoms of these childhood anxiety disorders and improve the children's overall quality of life

Each method had their own supportive reasoning for aiding the child in the treatment process. Art therapy provided a playful, nonthreatening, and engaging environment for the clients. Most children do not have the cognitive abilities to communicate their feelings and problems using words; art therapy provided a nonverbal communication outlet. It allowed the clients to express their emotions and communicate them to the therapist in a safe manner. This 
provided an avenue for self-awareness, as well as providing the therapist with a way to understand what the clients were saying.

Furthermore, the therapist utilized the CBT and DBT methods to teach the clients tips and tools that would help them rationalize their thoughts and change their behavior as a result. By teaching the clients and their families these coping mechanisms, the children could utilize these skills to normalize their lives again. The therapist applied art therapy, CBT, and DBT into a collaborative therapeutic model in order to have success with the clients and their families.

2. The art therapy, CBT, and DBT activities included in the collaborative therapeutic model were responsible for the children's marked improvements

Through the utilization of the collaborative therapeutic activities in the Art with Heart Organization's Chill \& Spill (2015), Draw It Out (n.d.), and “Mixed Emotions" cards, the therapist was able to determine the motivations for the different forms of anxiety in her two clients. Client \#1 exhibited symptoms of GAD and OCD because she wanted to keep the people and belongings she loved safe from harm. Client \#2 exhibited symptoms of PTSD because of previous trauma from sexual assault, as well as neglect and bullying from home and school. Through these collaborative therapy activities, the therapist was able to draw conclusions on what the clients were feeling and why. Therefore, the therapist could use the therapeutic art activities with the CBT and DBT coping mechanisms/skills activities to reduce the clients' negative thoughts and behaviors.

3. The factors of family and social support, as well as the therapist maintaining a good rapport with the clients, affected the children's progression during treatment.

The therapist created a safe and friendly environment, including the fact that the therapist maintained good rapport with both clients. An environment, such as this, allowed the clients to 
trust the therapist and express their feelings and issues. This provided room for improvement during therapy sessions. As much as there were improvements in the two clients, one client progressed much faster during treatment than the other due to the effects of family and social support. Client \#1 had immense family and social support during treatment. Her family would bring her to therapy and utilize the skills and methods the therapist taught outside of the therapy sessions to reduce her GAD and OCD symptoms. Whereas, Client \#2 had little family and social support during treatment. Only certain family members supported Client \#2, while the other family and school members continued to neglect and bully her. This resulted in a one step forward, two steps back form of progress during treatment. Fortunately, progress was still seen especially after Client \#2 was removed from the home that affected her negatively. 


\section{CHAPTER FIVE}

\section{Discussion}

Through the accumulation of data, analysis, and findings, it appears that the proposed collaborative therapeutic model consisting of art therapy, CBT, and DBT methods can be valuable in treating childhood GAD, OCD, and PTSD. The exploratory case study provided a means to analyze a collaborative therapeutic model that supplemented art therapy with CBT and DBT in a critical manner, allowing it to be researched and implemented in the future. Drawing on the therapist's expertise in working with children impaired by GAD, OCD, and PTSD, the case study participant provided valuable feedback in understanding the three therapy methods utilized. The collaborative therapeutic model will likely provide children with a broader approach to therapeutic methods that utilize holistic approaches adjacent to evidence based methods.

Art therapy could provide a playful, nonthreatening, and engaging environment for the clients. Since most children do not have the cognitive abilities to communicate their feelings and problems using words, art therapy could provide a nonverbal communication outlet. It could give the clients an opportunity to express their emotions and communicate them to the therapist in a safe manner. This could provide an avenue for self-awareness, as well as provide the therapist with a way to understand what the clients are saying. Furthermore, utilizing CBT and DBT within therapeutic model could teach the clients tips and tools that would help them rationalize their thoughts and change their behavior as a result. This could teach the clients and their families coping mechanisms that could normalize the child's life in turn.

Furthermore, the utilization of the Art with Heart Organization's collaborative therapy activities could determine the motivation for the different forms of anxiety in the clients, as well 
as draw conclusions on what the clients are feeling and why. Therefore, the therapist could be able to introduce therapeutic art activities with CBT and DBT coping mechanisms/skills activities to reduce the clients' negative thoughts and behaviors.

Lastly, the factors of family and social support, as well as the therapist maintaining good rapport with the clients, could affect the children's progression during treatment. Creating a safe and friendly environment includes maintaining a good rapport with clients. An environment, such as this, could allow the clients to trust the therapist and express their feelings and issues. This could provide room for improvement during therapy sessions.

There were definitive marked improvements in the clients' thoughts, emotions, behaviors, and overall quality of life, that resulted from implementing art therapy, CBT, and DBT together within a collaborative therapeutic model during treatment of their various childhood anxiety disorders. Overall, the results of this study could indicate that supplementing art therapy with CBT and DBT within a collaborative therapeutic model could assist in providing relief for children impaired by GAD, OCD, and PTSD. Although the exploratory case study method was successful in providing feedback in creating a collaborative therapeutic model, there were limitations through the process of the study. The case study client participants had similar backgrounds including similar demographics (both were female, West Virginia residents, and impaired by childhood anxiety disorders). If participants had a broader range of backgrounds, it may have informed the collaborative therapeutic model differently.

According to the literature discussed previously, continued research into effective treatments for childhood anxiety disorders is imperative. The literature implied that art therapy, CBT, and DBT each have the potential to be beneficial; however, devising a collaborative model 
including all three of the therapy methods is only the beginning. Future and ongoing research is necessary for the validation of the proposed curriculum.

Further research should be more specifically focused where first group client participants would exclusively receive only art therapy, the second group would receive only CBT, the third group would receive only DBT, and the fourth group would receive all three therapeutic methods. However, with the results obtained there is a strong indication that all three therapeutic approaches should be used within a collaborative model, as they will cater to the treatment of childhood GAD, OCD, and PTSD. Subsequently, as trends begin to emerge during treatments, the therapists should be able to identify children who seem to benefit from one type of therapy approach and concentrate on that to ensure that they do not fall behind in treatment of the clients' problems. Recommendations for future research include implementing this collaborative therapeutic model in school classrooms. Each individual method is already used in schools, work places, and other facilities. Thus, implementing the collaborative therapeutic model consisting of art therapy, CBT, and DBT could benefit children with various problems in school classrooms.

Childhood anxiety disorders will inevitably continue to occur and will continue to have long-lasting effects on the cognitive and emotional development in children, as well as their overall quality of life. However, the collaborative therapeutic model, pending further research, could fill the gap between the literature on the most efficacious ways to treat childhood anxiety disorders. 


\section{REFERENCES}

American Art Therapy Association. (n.d.) What is art therapy? Retrieved from http://www.arttherapy.org/upload/whatisarttherapy.pdf

Art with Heart. (n.d.). Draw it Out. Seattle, WA: TCC Printing \& Imaging.

Bayles, C., \& Villalobos, T. (2015). Using mindfulness with treatment of dual diagnosis in adolescents. International Journal of Behavioral Consultation \& Therapy, 9(4), 23-25. http://dx.doi.org.www.libproxy.wvu.edu/10.1016/j.chc.2011.01.011

Benjamin, C. L., Puleo, C. M., Settipani, C. A., Brodman, D. M., Edmunds, J. M., Cummings, C. M., \& Kendall, P. C. (2011). History of Cognitive-Behavioral Therapy in Youth. Child and Adolescent Psychiatric Clinics of North America, 20(2), 179-89.

Case Studies. (n.d.). In Writing@CSU. Retrieved from http:/writing.colostate.edu/guides/guide.cfm

Dialectical Behavior Therapy. (2016). In Goodtherapy.org. Retrieved from http://www.goodtherapy.org/learn-about-therapy/types/dialectical-behavioraltherapy\#History\%20of\%20Dialectical\%20Behavior\%20Therapy

Geller, Daniel A. (2006). Obsessive-Compulsive and Spectrum Disorders in Children and Adolescents. Psychiatric Clinics of North America, 29(2), 353-370. http://dx.doi.org/10.1016/j.psc.2006.02.012

Green, V. (Ed.). (2003). Emotional development in psychoanalysis, attachment theory and neuroscience: Creating connections. New York: Brunner-Routledge.

Harned, M. S., Dexter-Mazza, E. T., Murray, A., Comtois, K. A., Linehan, M. M., \& Chapman, A. L. (2008). Treating Co-Occurring Axis I Disorders in Recurrently Suicidal Women with Borderline Personality Disorder: A 2-Year Randomized Trial of Dialectical Behavior Therapy Versus Community Treatment by Experts. Journal of Consulting \& Clinical Psychology, 76(6), 1068-1075. doi:10.1037/a0014044

Hayes, S. C. (December 07, 2004). Acceptance and Commitment Therapy, Relational Frame Theory, and the Third Wave of Behavioral and Cognitive Therapies. Behavior Therapy, 35, 4, 639-665. http://dx.doi.org.www.libproxy.wvu.edu/10.1016/S0005-7894(04)800133

Herbert, J. D., \& Forman, E. M. (2011). The Evolution of Cognitive Behavior Therapy: The Rise of Psychological Acceptance and Mindfulness. In J. D. Herbert, E. M. Forman, J. D. Herbert, E. M. Forman (Eds.), Acceptance and mindfulness in cognitive behavior therapy: Understanding and applying the new therapies (pp. 3-25). Hoboken, NJ, US: John Wiley \& Sons Inc. 
Hoffmann, B. (2016). The Role of Expressive Therapies in Therapeutic Interactions; Art Therapy - Explanation of the Concept. Trakia Journal of Sciences, 14(3), 197-202. doi:10.15547/tjs.2016.03.001

Jacobs, J., McCall, A., \& Lorig, S. (2015). Chill \& Spill Leader's Companion: Supporting Youth through Creative Expression. Seattle, WA: TCC Printing \& Imaging.

Junge, M. B. (2010). The Modern History of Art Therapy in the United States. Springfield: Charles C Thomas.

Kabat-Zinn, J. (1994). Wherever you go, there you are: Mindfulness meditation in everyday life. New York: Hyperion.

Kostyunina, N. Y., \& Drozdikova-Zaripova, A. R. (2016). Adolescents`School Anxiety Correction by Means of Mandala Art Therapy. International Journal of Environmental \& Science Education, 11(6), 1105-1116. doi:10.12973/ijese.2016.380a

Krauss, S. E. (2005). Research paradigms and meaning making: A primer. The qualitative report, 10(4), 758-770.

Kuban, C. (2015). Healing Trauma through Art. Reclaiming Children \& Youth, 24(2), 18-20.

Linehan, M. M., \& Wilks, C. R. (2015). The Course and Evolution of Dialectical Behavior Therapy. American Journal Of Psychotherapy, 69(2), 97.

Leenarts, L., Diehle, J., Doreleijers, T., Jansma, E., \& Lindauer, R. (2013). Evidence-based treatments for children with trauma-related psychopathology as a result of childhood maltreatment: a systematic review. European Child \& Adolescent Psychiatry, 22(5), 269283. doi:10.1007/s00787-012-0367-5

Leon, A. C., Davis, L. L., \& Kraemer, H. C. (2011). The Role and Interpretation of Pilot Studies in Clinical Research. Journal of Psychiatric Research, 45(5), 626-629. http://doi.org/10.1016/j.jpsychires.2010.10.008

Mancuso, E., Faro, A., Joshi, G., \& Geller, D. A. (2010). Treatment of pediatric obsessivecompulsive disorder: A review. Journal of Child and Adolescent Psychopharmacology, 20(4), 299-308. doi:10.1089/cap.2010.0040

Merikangas, K. R., He, J.P., Burstein, M., Swanson, S. A., Avenevoli, S., Cui, L., ... Swendsen, J. (2010). Lifetime Prevalence of Mental Disorders in US Adolescents: Results from the National Comorbidity Study-Adolescent Supplement (NCS-A). Journal of the American Academy of Child and Adolescent Psychiatry, 49(10), 980-989.

http://doi.org/10.1016/j.jaac.2010.05.017 
Mills, E., \& Kellington, S. (2012). Using group art therapy to address the shame and silencing surrounding children's experiences of witnessing domestic violence. International Journal of Art Therapy: Inscape, 17(1), 3-12. doi:10.1080/17454832.2011.639788

Najjar, F., Weller, R. A., Weisbrot, J., \& Weller, E. B. (2008). Post-traumatic stress disorder and its treatment in children and adolescents. Current Psychiatry Reports, 10(2), 104-108. doi:10.1007/s11920-008-0019-0

National Alliance on Mental Illness. (n.d.a). Obsessive Compulsive Disorder. Retrieved from https://www.nami.org/Learn-More/Mental-Health-Conditions/Obsessive-compulsiveDisorder/Overview

National Alliance on Mental Illness. (n.d.b). Posttraumatic Stress Disorder. Retrieved from https://www.nami.org/Learn-More/Mental-Health-Conditions/Posttraumatic-StressDisorder

National Alliance on Mental Illness. (n.d.c) Psychotherapy. Retrieved from http://www.nami.org/Learn-More/Treatment/Psychotherapy

National Institute of Mental Health. (2016a). Anxiety Disorders. Retrieved from http://www.nimh.nih.gov/health/topics/eating-disorders/index.shtml

National Institute of Mental Health. (2016b). Obsessive-Compulsive Disorder. Retrieved from https://www.nimh.nih.gov/health/topics/obsessive-compulsive-disorder-ocd/index.shtml

National Institute of Mental Health. (2016c). Post-Traumatic Stress Disorder. Retrieved from https://www.nimh.nih.gov/health/topics/post-traumatic-stress-disorder-ptsd/index.shtml

Piacentini, J., \& Roblek, T. (2002). Recognizing and treating childhood anxiety disorders: These disorders are treatable but often are neglected by practitioners. The Western Journal of Medicine, 176(3), 149-151. Retrieved from https://www.ncbi.nlm.nih.gov/pmc/articles/PMC1071700/

Porta, M. S., \& International Epidemiological Association. (2008). A dictionary of epidemiology. Oxford: Oxford University Press.

Racco, A., \& Vis, J. (2015). Evidence Based Trauma Treatment for Children and Youth. Child \& Adolescent Social Work Journal, 32(2), 121-129. doi:10.1007/s10560-014-0347-3

Ritschel, L. A., Lim, N. E., \& Stewart, L. M. (2015). Transdiagnostic Applications of DBT for Adolescents and Adults. American Journal of Psychotherapy, 69(2), 111-128.

Rubin, J. A. (2010). Introduction to art therapy: Sources \& Resources (2nd ed.). New York: Routledge. 
Sarid, O., \& Huss, E. (2010). Trauma and acute stress disorder: A comparison between cognitive behavioral intervention and art therapy. The Arts in Psychotherapy, 37, 1, 8-12. http://dx.doi.org.www.libproxy.wvu.edu/10.1016/j.aip.2009.11.004

Sisemore, T. A. (2012). The Clinician's Guide to Exposure Therapies for Anxiety Spectrum Disorders: Integrating Techniques and Applications From CBT, DBT, and ACT. Oakland, CA: New Harbinger Publications.

Spinazzola, J., Rhodes, A. M., Emerson, D., Earle, E., \& Monroe, K. (2011). Application of yoga in residential treatment of traumatized youth. Journal of the American Psychiatric Nurses Association, 17(6), 431-444. doi:10.1177/1078390311418359

Stewart, S., Geller, D., Jenike, M., Pauls, D., Shaw, D., Mullin, B., \& Faraone, S. (2004). Longterm outcome of pediatric obsessive-compulsive disorder: a meta-analysis and qualitative review of the literature. Acta Psychiatrica Scandinavica, 110(1), 4-13. doi:10.1111/j.1600-0447.2004.00302.x

Tippit, Sarah. (2016). Art Therapy in OCD Treatment. Retrieved from https://www.intrusivethoughts.org/art-therapy-ocd-treatment-2/

Travers, M. (2001). What is qualitative research?. In Introducing Qualitative Methods: Qualitative research through case studies (pp. 2-14). : SAGE Publications Ltd doi:10.4135/9781849209724.n1

What is DBT?. (n.d.). In The Linehan Institute: Behavioral Tech. Retrieved from http://behavioraltech.org/resources/whatisdbt.cfm 


\section{APPENDIX A \\ Interview Transcription}

\section{* $\mathrm{RC}$ denotes the researcher}

*TH denotes the therapist

RC: Can you just state your full name and position at this business?

TH: Alright, my full name is XXXXXXX and I am a licensed graduate level, or masters level, social worker, and I'm a therapist at XXXXXXXX.

RC: Perfect, and what was the reason that you became interested in this job field before you went to school?

TH: Uh, in therapy?

RC: Mhmm.

TH: Well I actually went into social work more for advocacy and just wanting to do more community agencies and abuse prevention and different things. And as I went further into the program in my second year of internship was with the counselor's office at Mountain View Elementary School. So, you know [I] really took on a lot of therapy cases there. And when I got out of grad school, I did some more intervention-like young intervention-and then I went into advocacy for the waiver program. And then I said, "Hey, let's give therapy a shot!" So, that's my transition.

RC: Right, that's very neat. Now, you said when you went to your undergrad-you said you went into social work then?

TH: My undergraduate degree is in Speech Pathology and Audiology, and I did speech therapy for a couple years. 
RC: Okay, perfect.

TH: And then after that, I realized that there was just a huge discrepancy between seeing the kids that come in and actually their basic needs of being met. And you know I found that my interest was more in like what they were doing on a basic level of rather than just speakingRC: Just coming in and doing that and then leaving.

TH: Yes, so then I was like — so that's what really prompted me to go into you, know the advocacy.

RC: Right, and so that's when you went into your Master's, and that's when you went into therapy?

TH: Uh, yes. So, my first year internship was really advocacy through — anybody in the community could utilize these things. Good Lord, we had a free play group, a free preschool, there's a food bank, a baby bank — so you know, diapers and formula. And it's correlated with the shack, and they have tutors that go into my Milan Park Elementary. We did so much stuff—-home visits, education. And then second year internship I worked a little bit—in my first year internship she brought me on to do some stuff, but I did counseling in the school system [during second year internship].

RC: And what was the Masters title that you got?

TH: It's an MSW. My licensure is an LGSW.

RC: So, how did you find this place? What brought you here?

TH: So, I was working at Wellspring Family Services, and we do in-home therapy in the schools for people who have Medicaid. So, we would get a lot of referrals for CPS and different things, but they had a lot of wraparound services. And my coworker said that she saw a sign out front when they were building this office. She saw a sign that they were opening a counseling place, 
and I called. And I left a voice message, and I said I'm looking to do contract therapy. I specialize in Children and adolescents, and she called me back—Dr. XXXXX did. But it turns out that my last name was a flag for her because my sister-in-law, who has her doctorate in Psychology—when XXXXXXX, my sister-in-law, was in her undergraduate and Dr. XXXXX was in her doctorate program, XXXXXXX was her research assistant, and she [Dr. XXXXX] loved her. So, she heard the last name and was like, "How many XXXXXXX's can there be?" And so, she gave me a call, and we met, and it was just meant to be.

RC: Can you describe this place? I mean, obviously, you love working hereTH: I do love working here.

RC: Can you describe anything about it other than the fact that you like it? Like, what's it like coming in here every day? How many people do you see everyday usually? I know that there's people that come once a week or maybe not even that.

TH: So, we are just cohesive. I feel like we are all really supportive. We all really like each other, and we definitely have each other's backs. And that's important in an environment like this where you never know what's going to pop up, or what kind of support you need, or when custody cases come about, or when judges are going to try to subpoena your records, or you know, whatever happens. Dr. XXXXX - I love that she's so supportive. And also, when I have clients, and they are presenting symptoms - what we do is we treat the symptoms, whether or not whatever the diagnosis to me is, it doesn't necessarily matter as long as I'm treating the symptoms that they're presenting. But sometimes we need a little more information. So, I can always refer them [the clients] to her, and she will do an evaluation on them to give us a little more information. So, we can collaborate and that's really good. And we also just ask each other questions. How many clients I see a day? Typically, about 6 to 7. So, it's very broad because you 
have people who are scheduled, but not everybody comes. So, typically I have between 16 and 22 people scheduled a week. Sometimes all them come, sometimes I might only have 12 people. It just depends.

RC: It's interesting that you describe the way that this business is because, in my art therapy class, we just read a thing last night where they were talking about having a support system like that. Because like what you said, you never know what's going to happen in this kind of business. And how long have you been here exactly?

TH: Almost 2 years.

RC: And you said you were part time, correct?

TH: Based on the caseload, I would be considered a full-time therapist. But I'm only here-like I set my days, I set my schedule — so, I'm only here four days a week because I do most of my paperwork at home.

RC: Okay, that makes sense. And what are the age groups that you work with? I know that you have a lot of children that you work with, but I remember you talking about how you also work with older people and everything. So, basically [you work with] everyone?

TH: Yes.

RC: Okay, that solves that!

TH: My youngest is probably a three-year-old, but I don't actually work with him. I tried to make the guidelines really clear that I work with a family because, in that instance, a three-yearold is a three-year-old. Like, him coming in and spending an hour with me once a week isn't going to do anything for him. So, I need to teach the family the tips and tools and observe in [those] two things. So, I guess I go down [in age] pretty low, but that's not so much client but more family. 
RC: Right. Okay, can you name the methods you use and briefly describe each one?

TH: Alright. So, cognitive behavioral therapy — that is, um, it's very broad in the sense of - it's like an $\mathrm{ABC}$ model. So, you have an activating event [the 'A' part] which causes feelings. And then the ' $\mathrm{B}$ ' is your thoughts regarding the feelings. And then the ' $\mathrm{C}$ ' is your behaviors. So, in that realm, you really look to determine the thought process because people don't often-they feel it, and they think it. Therefore, it must be true. So, they don't stop to determine what the thoughts really are and rationalize it and validate—like use real world facts to line up to say, “Okay, just because I feel it, doesn't mean it's true.” And DBT is dialectical behavior therapy. It just takes the thought process into account, but it also throws in mindfulness and problemsolving skills. It talks about missing links. So, if you can process your thoughts and you have the problem-solving skills, but you're not utilizing it, like why? So, it has a bunch of different things. Goodness, summing it all up into a short thing is difficult. You also go into faulty belief systems. So, you might be able to rationalize a thought in theory, but your belief system is faulty. So, you can't truly rationalize that thought process because the belief behind it is there. If that makes sense.

RC: It does make sense

TH: So, the belief is validating that unrealistic thought. So, the narrative therapy gives somebody the ability to tell their story just from their perspective. And it also gives them the ability to make goals and make their life anything they want it to be. And they could just make it up as they go along - tell you how they want it to be. So, that just gives somebody the individuality of being a human being.

RC: Right, okay! That's a perfect summary I needed. Okay, so we have the two patients that I'm going to be focusing on. Should we discuss those, or do you think that the papers that you give 
me are going to be discussing it enough? Do they have backgrounds on them, or do I need to ask you anything about that?

TH: Let's see. Okay, let me give you background real quick because all that [other information] is in here. It's [the documents] just a pretty recent intervention that I've utilized and the treatment — so what we're really working on. So, I can give you a little bit of history on them. RC: Yeah, gender, age, and background would be perfect.

TH: Okay, so gender and age are on here. So, the first [client \#1] is the 10-year-old female. The background for her — she initially came in, and both of her parents brought her. And her little brother came in and really was struggling with, not so much generalized anxiety, but more so OCD—situational. So, there are certain situations where she might feel a threat. So, she might have anxiety about a specific situation, and she has to do a neutralizing event to try to make it better. She also would keep things, like useless things — paper, tags. She won't take some of her toys out of the boxes. She would worry about losing things. She puts a lot of pressure on herself - so perfectionism. And a big one is, which is very situational, she will fear-only on long trips like if they are going on vacation — that something will happen to her house. So, she wants to bring all of her things that are important to her with them on vacation, but she doesn't have that on a day-to-day basis. So, it's not like when she leaves the house she has to pack up all her stuff. It's only over an extended period. So, it's very situational. But even after seeing her twice - and I use the art with our curriculum and couple that with just general CBT workbook that I utilize. So, with two weeks she was like, "Hey I cleaned out my room. I got rid of the stuff. I decided I didn't want it anymore. I didn't like it. You know, I worry sometimes about forgetting my homework or not doing stuff right, but I know people aren't perfect." So, on and so forth.

RC: So, it's working. 
TH: Correct. But now, getting her parents to realize that it's not about not being anxious or not having that automatic thought because you can't control the automatic thought and the automatic feeling, but it's what you do with it. So, that's a big struggle that I find with all the kids that I work with. The parents feel like because it's still occurring-

RC: That it's not fixed.

TH: Correct. And like beating in their heads that's not going to happen [those thoughts are never going to go away].

RC: It's progress.

TH: Yeah, it's not going to happen.

RC: And how long have you been seeing this child?

TH: I don't think it [the document] has the initial date that I saw her. I can grab that on my computer.

RC: That's fine. You know, you were figuring out some of the issues she was struggling withthe OCD and the situational aspects of it-you just kind of figured that out from what she's told you, right?

TH: Well, initially what her parents reported — everything we do is self-report. Progress is selfreported. Also, things that I observe. So, the difference may be between what you observed yesterday and like what I observe - that is solely on self-report. Because when I observed the little boy [speaking about a previous observation] it's tough for me to see progress. That's a struggle for me. But when his mom comes back and says - he might not be able to verbalize the things, but the feedback that she [his mom] is getting just on his overall emotional state is more positive. So, he doesn't really give me what I need during session. But in this particular instance — this little girl — that has pretty high emotional intelligence. She's got a lot of family 
social support. She's got a high sense of confidence within herself. She feels really good about herself. But still balancing out [that] you can't control everything. What do I need to do? Is this a real fear? Am I really in danger of this? So, those things are successful, and she has the emotional intellect to comprehend it and use it.

RC: Right. And the methods that you said you used with her-you use CBT workbook-

TH: Mhmm. I use the art therapy, and I also did the DBT mindfulness.

RC: So, basically, a mixture of those three-

TH: And the narrative. So, the lump of it is going to be a mixture.

RC: And you said that has influence because of the self-reports that you have received —-things are dwindling, they are getting better, she's realizing that everything is not going to be perfectTH: Yes.

RC: And you said the factors in the patient's or client's life- the ones that affect them the most - I remember that we discussed that. Family was a big one. I guess, for her at least, she has a lot of support.

TH: Yeah.

RC: Is there anything else that you can think of that would affect—like an outside source like that [family support] — that is a big influence on both of these patients?

TH: I feel like being also involved in extracurricular activities - it gives them a sense of purpose. It gives them something to work for. It allows them to make friendships outside of school.

RC: So, kind of like getting out and trying to do something that gives them the purpose and helps them fit in, I'm sure.

TH: Yes. 
RC: What do you think is important in order for your relationship and progress to go with the patient?

TH: Rapport! So, if you don't have [good] rapport, you could be the smartest person in the world, and they don't care. I also feel like you could be the dumbest person in the world and, as long as they like you, they're going to listen to what you say.

RC: I completely believe that.

TH: So, you have to have a balance of knowledge and social skills.

RC: Has there ever been anything too serious for you to deal with — that you had to be like, "Hey we need to refer you to someone else." Has there ever been instances like that?

TH: Yes.

RC: And so, do you just refer them to, for instance Dr. XXXXX, or someone that canTH: This one family — it was a tough one. [The client's] Mom was the biggest barrier. It's been almost a year, and I'm still like PTSD-ing from this.

RC: That's another thing I was reading about last night was how it affects art therapists, or therapists in general.

TH: Yeah it can affect you. I've gotten a lot better at it. It takes time.

RC: Wow, okay. I guess what my next question would be is has there ever been also an instance where you knew a child needed more than something that you guys give them-like medicine.

TH: Yeah, we refer out.

RC: Okay, so that's how you handle those situations. So, back to the other client—age and gender.

TH: 14-year-old female. The diagnosis is on here as well. So, PTSD for her. Oh, history. So, [when] she came to see me, she was self-harming — she was cutting [and had] suicidal ideation. 
She had been hospitalized for suicide attempt. She had been in treatment for a year prior to coming to see me at an office just down the road. So, her mom actually brought her in. What was reported to me right then is she was raped at the age of 11. She had an inappropriate relationship with a man online for a year prior to that. She agreed to meet him [and] snuck out of her house. So, from the time she was 10 - sending inappropriate pictures of herself. He [the man from the internet] was urging her to self harm [and] she would take pictures of it. So, then you have to go into what makes 10 -year-old engage in an activity like that. So, he got her to meet him [and] sneak out. He picked her up, and he raped her. Since then, obviously, inpatient hospitalization, the year of treatment, mom and dad were separated. Right before she came in, it was agreed at the last therapist that she could live with dad full-time and just see Mom every other weekend. Then, she stole alcohol in Middle School and took it to school and also had been in three fist fights. And dad said she couldn't stay there anymore like that. So, they went back to week-on, week-off at mom and dad's. And she had also transitioned into- - I forget what it's called. It's like an Alternative Learning Center. So, she wasn't being functional in the school setting. Since then, she's transitioned back into the public school. So, that was a pickle, and figuring out how to treat her symptoms that she was presenting with right then. And also, clearly, a lot of past trauma to figure out. What happened in the past to bring a 10-year-old to want to do that? So, what are we doing now, and how did we get where we are right now? So, it was a really tricky one.

RC: So, obviously, factors that influenced that patient's life - I mean dealing with mom and dad separated probably affected things. Does she have a lot of support from her parents though even though they're separated? 
TH: Well, this is what we started with. She was in a crisis state. So, mom made the call to bring her in. Mom was dissatisfied with the other therapist because the other therapist prompted for her to go live with dad, and they all agreed — even though it was against the custody arrangement. Mom brought her in twice a week for me, and I usually don't ever do that. So, we did that for a good two months. And then stepmom brought her one week, and mom got really upset the stepmom got involved. We were able to scale back to once a week because I feel like she had stabilized a little bit. So, we agreed mom would bring her one week [and] stepmom would bring her another week. So, I was still seeing her at least once a week. And then mom discontinued bringing her for treatment. So, stepmom was still bringing her every other week. Called mom, voicemail wasn't set up. She wouldn't answer the phone. So, from—about the three or 4-month mark-I went from twice a week to once a week at the 4-month mark just to every other week because that's all the availability that we had. Since then, CPS has removed them [the children] from the home - from their mom's home — and her and her siblings are staying with dad. That was just a recent occurrence. So, she's staying with dad now. We are waiting for the court hearing for the final sayings for custody. But throughout my time seeing her, even when mom was here, [she said] "I want to live with Dad. I want to live with Dad. I'm uncomfortable at your [mom's] house. I want to live with Dad. I want to live with Dad." So, that obviously lets you know that the trauma and the neglect were really occurring, more so, at mom's. So, it's still not giving me a whole bunch of information, other than, "I want to live with Dad because I'm uncomfortable with mom's. We have to stay in our rooms until she gets up. We're not allowed to eat." So on, and so forth. So, dealing with the assault, the current abuse and neglect that's going on, the symptoms that go along with it, and dealing with the past neglect and abuse has been really trying. 
RC: Yeah. That seems like progress would be hard to make. Did you ever seem to figure out what caused her to do that at 10 years old? Did you ever get down to that?

TH: Yeah she'll say mom and stepdad we're calling her a 'whore' and 'stupid' and 'fat' and lots of bullying at school. Mom was very, very rigid with them [the children]. I think there was drug abuse in the home, and the kids had to stay in their rooms the whole time when they were at the mom's house. The mom wouldn't cook, but they could only eat at certain times. And even if they were in their rooms, they had to be really quiet. So, her grandma actually bought her a phonewhich is mom's mom. Everybody's been calling CPS this whole entire time-stepmom, dad, teachers - and it's been a really difficult period. So, mom's mom bought her the cell phone so she could call her at any point in time. She found a male who was older, who she looked at as a role model [and] who would listen to the things and listen to her vent. She would tell him about what mom was doing and saying. And, obviously, he's in prison now. So, yeah just the past things, but then recognizing that stuff is still occurring.

RC: That's so hard for recovery if it's not going to change. Which brings us back to the whole point of family support is a huge thing for these children to get past [their issues].

TH: So, I kind of looked at it as she can come in here and have a healthy way to vent.

RC: Have you seen any progress at all because of how hard it is right now with the whole family situation?

TH: Absolutely. I mean it's always been one step forward and two steps back. But using the tips and tools, learning about healthy relationships, learning about attachment, having the ability to get out current feelings through art therapy, past trauma, all of that stuff.

RC: And you've used all those methods, and it's helped her to do that? 
TH: Yes, and the narrative, too, can go into writing letters about what we're feeling, about what we wish would change, getting out angry feelings, any of that stuff.

RC: How have you noticed progress? What has been changing with her?

TH: Her grades are improving, she's gone back to public school. Anger was her go to thing. So, that has been so difficult to get her to process her anger because she will tell you it's just uncontrollable. It's not uncontrollable. So, getting her to recognize it was a defense mechanism she was using to make herself feel more powerful in a situation that's out of her control. So, I don't need to be angry. She has not been in a fist fight. Even assaulting her dad and her siblings - that's not been reported, at least, for 4 months. So, aggressive behaviors have improved. They say even just watching her in school and making new friends and feeling comfortable and following the rules — "May I go here? Okay, I'll be back at this time.” Doing that as opposed to just taking off and walking down the road. So, respect in the household rules [and] respecting herself. She reports a decrease in cutting. So, the situation is still feeling kind of hopeless at mom's. But now, the past month, has really improved but still kind of waiting to see, “Do I have to go back to Mom's?” But I feel like if she doesn't have to go, then we are starting a whole new thing of really dealing with everything. So, when she feels safe, [she will] really [be] dealing with everything that she's been through. It's just multi-faceted.

RC: That 10-year-old female that we were talking about with the OCD and stuff-Was there ever a reason why that was happening? Or was it just have her personality was?

TH: She just is. Anxiety always serves a purpose. I mean, you want to ask if it's the environment, if its genetics, [or] if it's a particular situation. It really depends. Mom reports that she's anxious. So, I feel like it's multi-faceted. It's a biosocial theory. So, the environment and 
biology really play a role. So, whether it was modeled for her and kind of a little bit ingrained in her. Probably a little bit of both.

RC: Mixture just of the surroundings and everything.

TH: Yes. Anxiety always serves a purpose and, more than likely, it's to keep you safe.

RC: I forgot to ask you actually, do you know down the road how long you'll have to see these people? Or is it just kind of like we're waiting to see?

TH: I always try to take things_-for the first month I want you to come see me once a week. If you're in crisis, I would do 2 times a week for the first month and gage where we are. So, those things are all based on self-report and what I'm seeing. People who come here are not courtordered. I mean, other people have some probation. So, my clients are not court-ordered. So, at any point in time they can decide not to come back here at all.

RC: Right. They might just think they are doing better and-

TH: Yes so it's more like: How do you feel? What progress do you see? What things are you still struggling with? And then, depending on that, when I feel like I've taught them the foundation for everything, I scale back and I let them use it in their everyday life. So, I go from the process of at least once a week for the first month. Usually I don't scale back to every other week in the first month, except for in this little girl [the 10-year-old with anxiety and OCD]. She was just pretty quick. Like, okay I see progress. Mom was like, “Great!” None of her symptoms were intense when she came in. So, probably I think I saw her for 2 months and then at 1 time a week. [That] turned into every other week. When she reports like, "Okay, I'm going all this time and I'm still seeing a lot of progress," then I will do once a month for a couple months just to touch base. And then you call me if you need me. I feel like the 14-year-old [however] will be a repeat offender. Probably all throughout her life. 
RC: Because it's such a big struggle?

TH: Yeah. Now, the 10-year old girl [with anxiety and OCD]—I think she'll need bouts here and there of therapy, but her emotional intelligence is pretty good. So, I don't think she'll need consistent [therapy]. So, I would say I give her probably every 5 years, if she transitions into new things, [that] she might need a little bout-

RC: Because of change?

TH: Yeah. Reinforce the tips and tools and let her process some stuff. Now, the brain is modified by the trauma and the other things. But we can really create - process the trauma and do the new neuropathways, which is a process. But she's going to need consistent reinforcement probably throughout her life [14-year-old female with PTSD].

RC: The 14-year-old female, we talked about using all of those methods, but what do you think has been the best for her?

TH: To be really honest with you, I don't even know if it's an actual therapeutic model that's the best for her, but I think it's just having somebody who listens to her and validates her and tells her that it's going to be okay. In reinforcing those therapeutic models, having a supportive adult is helpful and somebody to give feedback to her parents - like her stepmom and her dad who play an active role. What can you [parents] really do to support her? I feel like starting off, dissecting the self-harmful behaviors and talking about the anger being on the surface-if I feel angry at myself, I'm not going to hurt myself. If I feel angry at others, I'm not going to punch you in the face — really feeling inadequate, having a real low sense of self, feeling really sad and depressed about a situation, feeling hopeless and powerless. So, anything we can do to gain personal awareness as to what she's really feeling and why — what makes you feel that way? Okay. when you're feeling that way, [utilize those] coping mechanisms. 
RC: Now, what about narrative that we were talking about? Have you seen personal awareness and stuff through that?

TH: Yes.

RC: Through the art, how have you seen that? When you look at her art and stuff, how do youTH: When she's able to tell her story from her perspective-mom's main thing is that she's going to tell you that she's lying. And that she's doing it for attention, and she's making stuff up. So, when she's really able to tell her story — her perception of it—when she's able to draw it out, when she's able to write it out, when she's able to use clay and mold stuff, when she's able to put animals to people — and why are they that animal and what does that mean — that's all about gaining personal awareness as to how she views people. It gives me awareness too. So, when she can tell her story and have somebody sit back and validate it.

RC: Now the 10-year-old female that we were talking about — the one that has just the anxiety and OCD—we talked about using the CBT workbook, art therapy, all those things. Which method do you think has really helped her the most?

TH: CBT. I mean art is good for all of them in terms of their development. So, it's just another therapeutic medium that I can have.

RC: What's an example of something that you could give me of a CBT [activity] that has worked for her?

TH: So, for instance let me read you this little excerpt. So, these two things go together. "Working focused on identifying anxious thoughts and reading them on a fear thermometer." So, that's the first step when you're doing any sort of anxiety or OCD training. What's really bothering you? What's anxiety mostly provoking for you? And what gives you anxiety? But not so much that it's like crippling for you. You want to start at the bottom so that you can have 
success is with that. So, you're going to train them on actual rationalizing, recognizing what faulty beliefs they hold about the situation, and how that reinforces the thought process that goes into it. So, getting them to recognize that a thought is just a thought and a feeling is just a feeling. What is the evidence of danger here? I know my fear thermometer is going off [but] on what level? Is there real Danger? So, if I don't have danger here, okay, I'm going to take a couple deep breaths. What's really bothering me? So, those are the things that we utilize CBT. And you can do that thought process in your head, and she has the emotional intellect to utilize it. So, that's what's helpful.

RC: And with the art portion of that does she - after using CBT and stuff-does the art help kind of like push that a little bit further. Kind of like, does she illustrate that through art?

TH: What I actually more so use in the art for her [the 10-year-old with anxiety and OCD] is for social support. So, to get it [anxieties] out and to be able to show me what's really going on, and it also reinforces leaning on others. So, who can you go to when you are feeling anxious? You don't have to feel anxious by yourself. It doesn't always have to be in your head. Go to your mom and say, "Mom I'm really anxious about da da da da...," and what I want mom to do is validate. "It is okay that you are anxious. Can I do anything to help you? Do you need a hug?" Another big CBT tool, worst case, best case reality. What am I really afraid of? Worst case scenario - the worst thing that could happen. What would it be? If that happened could I live with it? Best case is if the best thing could happen, obviously. And in reality, what's most likely going to happen? And it's usually not the worst case.

RC: I feel like that's it! Perfect amount of time too. I'm sorry to hold you up, and if I have any more questions, I'll ask them over email. Thank you!! 


\section{APPENDIX B}

\section{Email Messages}

\section{Part 1: Questions \& Answers}

Question \#1: How did you diagnose each patient that I'm discussing in my research paper?

a. Did you just use the communication with client, patient, and school to figure out the issues and diagnose from that?

Therapist's Answer: If the client comes in for their first session and hasn't been

previously diagnosed by a psychiatrist or psychologist, I utilize the symptoms reported by to make a diagnosis. With the two clients you are doing research on, I utilized client/family reports to make a diagnosis. The PTSD client had previous mental health services; however, I did not request those records and made a diagnosis based on client/family report.

b. Did you diagnose from your own observations?

Therapist's Answer: My initial diagnosis is from family/client self-report of symptoms. After seeing a client for a while, if I observe that the client's symptoms aren't lining up with the diagnosis or if they report a change in symptoms, I can change it. I have not changed the diagnosis for either of the clients you are doing research for.

Question \#2: What are the aims of the therapeutic activities utilized?

Therapist's Answer: With each activity work with the clients to communicate difficult issues, reduce stress, and normalize feelings. We also aim to increase interpersonal skills, manage reported symptoms, and increase self-esteem and self-awareness. 
Question \#3: What were your findings from the art therapy, CBT, and DBT activities?

Therapist's Answer: The findings are different every time. I focus on linking events, feelings, thoughts, and behaviors. The focus will be on what events occurred throughout the week. My main goal with this is for the client to be able to recognize what they are feeling, why they are feeling that way, what has made them feel that way, and how they responded to the thoughts/feelings. We focus on finding facts to the situation so we can rationalize thought patterns and decrease the intensity and duration of intense negative feelings.

Question \#4: Were there ever times you did a family counseling session with any of the clients? Why? When in their treatment? What happened?

Therapist's Answer: I meet with the families at the end of every session. It's vital for the caregivers to know what tools to utilize/reinforce with the client. I give caregivers information on tips/tools learned, answer any questions they have, and get a report on observations they made during the week.

Question \#5: What disorders/issues did the client I observed suffer from, and what methods of therapy did you use during the session?

Therapist's Answer: The female is diagnosed with ADHD by history- she had an assessment completed prior to treatment with me and was diagnosed with that- I see her for behavioral issues resulting from symptoms. I utilized a draw it out activity, and we did an art activity that focused on creative expression and then telling a story about her picture adding in feelings. 


\section{Part 2: Therapist's Notes on the Two Clients}

The female with anxiety symptoms reported anxiety over family becoming ill (no one is sick); hoarding items; afraid favorite items will get lost; afraid of failing homework/tests. Utilized CBT, DBT, and narrative therapeutic models. Through therapeutic process, it has been determined that the motivation for anxiety is to keep others/things she loves safe and preventing feared situations from occurring. Education regarding anxiety is presented during every sessionevents, feelings, thoughts, actions discussed during every session- CBT, DBT skills, and Narrative Therapy are also utilized. All skills are used in combination with art and play. Reported from client and mom- client not seeking as much reassurance from mom about feared situations and she is engaging in situations that would previously cause anxiety without having a "melt down". Improvements also reported on obsessive thoughts surrounding anxious situations.

PTSD female- depressive symptoms, anxious symptoms, panic, self-harmful behaviors, angry outbursts, physically assaulting others, alcohol abuse, and failing school. Every sessionutilized art/journaling/emotion cards- CBT, Narrative Therapy, DBT, education regarding trauma, anxiety, depression and cutting behaviors. Lots of processing core emotions and events. setbacks including mom discontinued to bring to session, continued abuse/neglect from mom. Client has been removed from mom's home for 2 months. Client worked hard to understand events and core emotions and how she acting on the emotions. Has not physically assaulted others in 4 months, no cutting behaviors for 5 months, more respectful towards others, going to school/tutoring and passing classes. Reports improved feelings of anxiety and depression and 
less isolation. Only feels extreme sadness about $1 \mathrm{x}$ week instead of every day. When sad/anxious she uses learned CBT DBT skills and will communicate with others what is really bothering her.

\section{Part 3: Therapist's Notes on Combining Therapeutic Methods}

I combine these models because on the kid/family side the art therapy is playful, nonthreatening, and engaging. Most children don't have the cognitive ability to express their issues and frustrations with words, or skills to sort out difficult feelings on their own. Art therapy is another way of communication for clients, it allows them to put thoughts/feelings/ideas/beliefs into art which helps them with self-identification and verbalizing thoughts and feelings. I incorporate the other therapeutic models because it's what I know works. I use these skills to help me read what the child is trying to say. I also use the therapeutic models because it has useful tips and tools to send home with the kids/families to use during the week to address areas of concern. It's not enough to just know what's bothering someone and process it in session (that's only 1 hour a week), you have to be able to give them real life coping skills to help them in their everyday life and also teach their family skills to help themselves and the child. I have to combine all of the aforementioned techniques to have success with my client's and their families. 


\section{DBT Cheat Sheet Utilized During Therapy}

\section{DBT CHEAT SHEET}

How to use these
skills:
Awareness
Acceptance
Action

Mindfulness

How skills:

- One-mindfully

- Non-judgmentally

- Effective

What skills:

- Observe

- Describe

- Participate

Distress Tolerance

Activities

Contributing

Comparisons

Emotion opposites

Pushing away

Thoughts

Sensations

Imagery

Meaning

Relaxation

One thing at at time

Vacation

Encouragement

Temperature

Intense Physical

Exertion

Paced breathing

Emotion Regulation

Skills

- Understand

emotional experience

- Reduce emotional

vulnerability

- Decrease emotional suffering
Emotion Regulation

P \& L Physical IIIness

(treat)

Eating (balance)

Altering drugs (avoid

mood-altering drugs)

Sleep (balance)

Exercise (get)

build M A S T E R y

Mindful to emotion

Act opposite to emotion

Self-validation

Turn the mind

Experience building

positives

Radical acceptance

Interpersonal

Effectiveness

Describe

Express

Assert

Reinforce

Mindful

Appear confident

Negotiate

Gentle

Interested

Validate

Easy Manner

Fair

Apology-free

Stick to values

Truthfulness

Problem Solving

1.Identify problem

2. Gather data

3. Analyze data

4. Find solution
Validate

Imagine

Take small steps

Applaud yourself

Lighten your load

Sweeten the pot

Setting Goals

Specific

Meaningful

Achievable

Recordable

Timeline plan

Relapse Prevention

- Practice skills daily

- Enhance positive

states

- Disregard social

pressure

Thought

Modification

- Turn the mind

- Radical acceptance

-Willingness

Behaviour Chain

Analysis

1.Prompting event

2.Problem thought

3. Problem emotion

4. Target behavior

5. Short-term relief

6. Long-term consequences

\section{Self-soothe with \\ the senses \\ Taste \\ Hearing \\ Smell \\ Sight \\ Touch}

Pros \& Cons

\section{THINKING}

DIALECTICALLY:

Maintain openness to contradictory and/or polarized thoughts and points of view. Blend these thoughts into a "truth" which best explains reality at the moment.

\section{WISE MIND:}

Emotional mind is the feelings mind. Reason mind is the factual/ knowledge mind. Wise mind is when they work together with intuition.

\section{OBSERVE, JUST} NOTICE: Look at the situation without emotion or judgment. Just notice what is happening without trying to change it.

4. DESCRIBE: Put words on it. Describe the event without judgment or emotion. "Just the facts."

\section{NON-JUDGMENTAL} STANCE: Avoid labelling something as "good" or "bad." Just observe, describe, participate.

\section{EFFECTIVENESS:}

Focus on what works. Keep an eye on your objectives.

7. MINDFULLY: In the moment. Focus all of your senses on the one thing you are doing/thinking at a particular moment. If you notice other thoughts entering your mind, follow them, but let them go. 